\title{
AN OVERVIEW OF CONSTITUTIVE MODELS FOR SHAPE MEMORY ALLOYS
}

\author{
ALBERTO PAIVA AND MARCELO AMORIM SAVI
}

Received 1 September 2004; Revised 27 September 2005; Accepted 5 October 2005

The remarkable properties of shape memory alloys have facilitated their applications in many areas of technology. The purpose of this paper is to present an overview of thermomechanical behavior of these alloys, discussing the main constitutive models for their mathematical description. Metallurgical features and engineering applications are addressed as an introduction. Afterwards, five phenomenological theories are presented. In general, these models capture the general thermomechanical behavior of shape memory alloys, characterized by pseudoelasticity, shape memory effect, phase transformation phenomenon due to temperature variation, and internal subloops due to incomplete phase transformations.

Copyright (C 2006 A. Paiva and M. A. Savi. This is an open access article distributed under the Creative Commons Attribution License, which permits unrestricted use, distribution, and reproduction in any medium, provided the original work is properly cited.

\section{Introduction}

The interest on intelligent materials has grown in the last decades due to their remarkable properties. This class of materials, usually applied as sensors and actuators in the socalled intelligent structures, has the ability of changing its shape, stiffness, among other properties, through the imposition of electrical, electric-magnetic, temperature, or stress fields. Nowadays, the most used materials on intelligent structures applications are the shape memory alloys, the piezoelectric ceramics, the magnetostrictive materials, and the electro- and magnetorheological fluids.

Shape memory alloys (SMAs) are metallic alloys that are able to recover their original shape (or to develop large reaction forces when they have their recovery restricted) through the imposition of a temperature and/or a stress field, due to phase transformations the material undergoes. SMAs present several particular thermomechanical behaviors. The main phenomena related to these alloys are pseudoelasticity, shape memory effect, which may be one-way (SME) or two-way (TWSME), and phase transformation due to temperature variation.

Hindawi Publishing Corporation

Mathematical Problems in Engineering

Volume 2006, Article ID 56876, Pages 1-30

DOI 10.1155/MPE/2006/56876 
In order to explore all potentialities of SMAs, there is an increasing interest on the development of mathematical models capable to describe the main behaviors of these alloys. SMA thermomechanical behavior can be modeled either by microscopic or by macroscopic points of view. The first approach, actually, considers either microscopic or mesoscopic phenomena. The microscopic approach treats phenomena in molecular level while mesoscopic approach is related to the level of lattice particles, and its modeling assumes negligible fluctuations of the molecular particles. These approaches have been studied by several authors including Warlimont et al. [82], Perkins [57], Nishiyama [52], Achenbach, and Müller [3], Sun and Hwang [75, 76], Fischer and Tanaka [21], Comstock et al. [15], Lu and Weng [43], Levitas et al. [39], Gall et al. [26], Sittner and Novák [71], Kloucek et al. [34], Muller and Seelecke [49], among others. On the other hand, the macroscopic approach is interested in SMAs' phenomenological features. In the following paragraphs, the authors briefly discuss some macroscopic models found in the literature, which will be better explored later on in the paper.

Falk [17, 18] and Falk and Konopka [19] propose a one-dimensional model based on Devonshire's theory. This model assumes a polynomial-free energy potential, which allows pseudoelasticity and SME description. The great advantage of Falk's model is its simplicity.

There is a class of models in literature known as models with assumed phase transformation kinetics that consider preestablished simple mathematical functions to describe the phase transformation kinetics. This kind of formulation was first proposed by Tanaka and Nagaki [78] that motivated other researchers who present modified transformation kinetics laws as Liang and Rogers [41], Brinson [13], Ivshin and Pence [32, 33], Boyd and Lagoudas [12], among others. These models probably are the most popular in the literature, and therefore they have more experimental comparisons, playing an important role within the SMA's behavior modeling context.

Other authors explore the well-established concepts of the elastoplasticity theory (Simo and Taylor [69]) to describe SMA's behavior. Bertran [9] proposes a three-dimensional model using kinematics and isotropic hardening concepts. Mamiya and coworkers (Silva [68]; Souza et al. [74]) also present a model capable of describing pseudoelasticity and $S M E$ behaviors using plasticity concepts. The models proposed by Auricchio and coworkers can be included in this class as well. Firstly proposed for a one-dimensional media (Auricchio and Lubliner [5]), the model was extended to a three-dimensional context (Auricchio et al. [7]; Auricchio and Sacco [6]). There are still other models that exploit plasticity concepts as those proposed by Govindjee and Kasper [29], Leclercq et al. [37], among others.

Knowles and coworkers (Abeyaratne et al. [1, 2]) present a one-dimensional model, which sets nucleation criteria for volumetric phases to express the internal variables based on the energetic barrier to be overlapped, so that phase transformations occur. Besides, the authors apply evolution laws for the phase transformation kinetics.

Fremond $[22,23]$ developed a three-dimensional model that is able to reproduce the pseudoelastic and shape memory effects by using three internal variables that should obey internal constraints related to the coexistence of the different phases. Afterwards, a new one-dimensional model, built up on the original Fremond's model, is developed 
and reported in different references (Savi et al. [66], Baêta-Neves et al. [8], Paiva et al. [56], Savi and Paiva [65]). This new model allows the description of a greater phenomena variety considering the effect of thermal and plastic strains, and including a plasticphase transformation coupling, which turns the TWSME description possible. Besides, this model also describes tension-compression asymmetry-a point of great relevance.

The goal of this work is to discuss the main features associated with SMAs, their applications, and their constitutive modeling. The models here presented constitute an important tool for application design.

\section{Metallurgical features}

Several authors have discussed SMAs' metallurgical features (Matsumoto et al. [47], Shaw and Kyriakides [67], Otsuka and Ren [54], Gall et al. [26], among others). The martensitic-phase transformation phenomenon is responsible for the remarkable SMA's properties. These transformations are nondiffusive processes involving solid phases that occur at a very high speed. Experimental studies (Wasilevski [83]) reveal that these transformations are caused by the free-energy difference between the microconstituent phases involved in the process, which induces chemical bond changes. Therefore, phase transformations can be interpreted as being essentially crystallographic.

Basically, there are two relevant microconstituent phases associated with SMAs-the austenite (stable at high temperatures) and the martensite (stable at low temperatures). While the austenite has a well-ordered body-centered cubic structure that presents only one variant, the martensite can form even twenty four variants for the most generic case (Funakubo [24]) and its structure depends on the type of transformation the material has undergone (Otsuka and Ren [54]; Wu and Lin [85]). The martensite usually forms plates known as correspondence variant pair $(C V P)$, due to the growth of two twin-related variants.

During phase transformation from austenite into twinned martensite (or temperatureinduced martensite (TIM)), a geometric crystallographic change occurs. However, there is one plane that does not suffer any distortion called habit plane. The nucleation process of each CVP begins with the appearance of a share stress in a parallel direction to the most favorably oriented habit plane of each crystal.

According to Gall et al. [26], the detwinned martensite (or stress-induced martensite $(S I M))$ formation process involves two distinct deformation mechanisms that do not occur simultaneously, namely the deformation due to martensite nucleation (CVP formation) and the deformation due to reorientation process (CVP detwinning). During the reorientation process, a considerable amount of strain takes place due to the growth of the most favorable oriented variant in relation to the loading direction. At the end of this detwinning process, a completely martensitic reoriented structure remains stable.

Experimental studies reveal that during the cooling process, there is an intermediate rhomboedral phase between martensite and austenite called R-phase, according to the differential scanning calorimeter (DSC) thermogram presented in Figure 2.1 (Shaw and Kyriakides [67]). Similarly to the martensite, the R-phase can be either temperature induced (twinned R-phase) or stress-induced (detwinned R-phase). Since the strain 


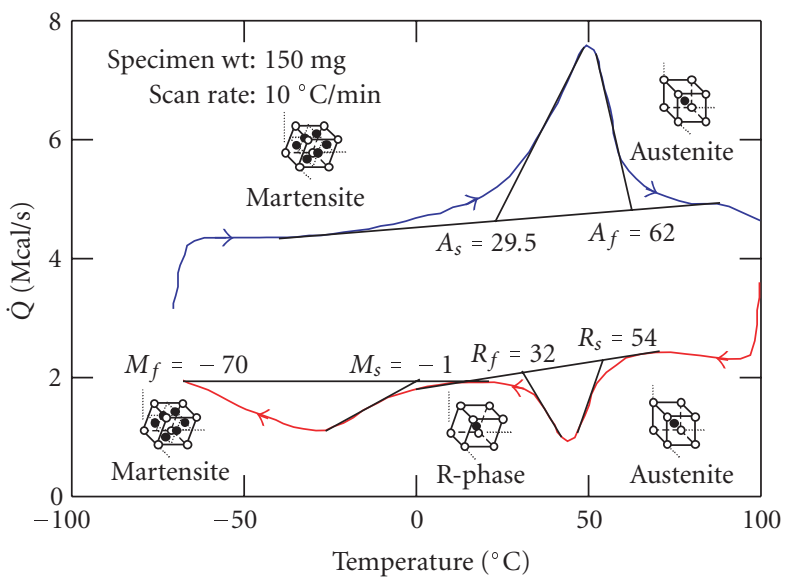

Figure 2.1. DSC thermogram for $\mathrm{Ni}-49.9 \mathrm{wt} \% \mathrm{Ti}$ alloy.

amount developed during R-phase detwinning process is insignificant as compared to the one developed during martensite detwinning process, it can be neglected.

Macroscopically speaking, for one-dimensional media analysis, it is enough to consider only three variants of martensite together with austenite $(A)$ on SMAs: the twinned martensite $(M)$, which is stable in the absence of a stress field, and two other martensitic phases $(M+, M-)$, which are induced by positive and negative stress fields, respectively.

The martensitic transformation creates strong orientation dependence, which influences tension-compression asymmetry (Gall et al. [26]). Several works on the literature verify this asymmetry for the most employed types of SMAs despite being mono or polycrystalline alloys. Sittner and coworkers observe the asymmetry phenomenon for mono (Sittner et al. [72]) and polycrystalline Cu-Al-Zn-Mn alloys (Sittner et al. [73]). Polycrystalline Fe-based alloys also exhibit this behavior (Nishimura et al. [50, 51]). Comstock et al. [15] and Sittner and Novák [71] certify this occurrence for polycrystalline Ni-Ti, $\mathrm{Ni}-\mathrm{Al}$, and $\mathrm{Cu}$-based alloys. Gall and coworkers also studied mono and polycrystalline $\mathrm{Ni}$-Ti that present tension-compression asymmetry (Gall et al. [25]).

According to the previously mentioned experimental studies, due to their strong orientation dependence (for monocrystal) or texture dependence (for polycrystal), SMA samples usually present higher critical transformation stress levels, smaller recoverable strain levels, and steeper transformation stress-strain slopes under compression tests.

SMAs Ni-Ti-based alloys (commercially known as Nitinol) present exceptional mechanical and physical properties with excellent biocompatibility; therefore, they have been the most employed in a great number of applications. The manufacturing process to obtain these alloys should be carefully observed, since small deviations from equal atomic proportion between Nickel and Titanium may produce $\mathrm{Ti}_{3} \mathrm{Ni}_{4}$ precipitates, which inhibit martensitic transformations and block up dislocation motions.

Besides tension-compression asymmetry, another important phenomenological feature related to SMAs thermomechanical behavior concerns plasticity. Plastic strains have 


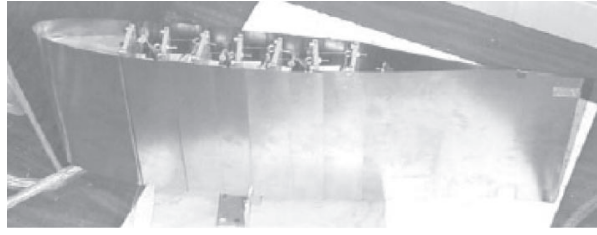

(a)

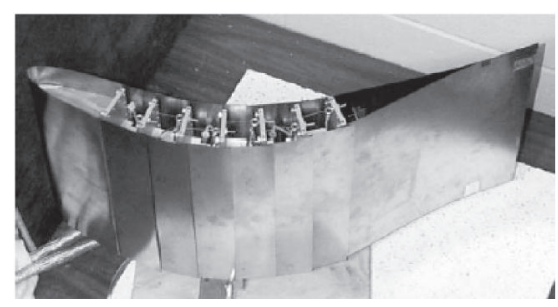

(b)

Figure 3.1. SMA multiactuated hydrofoil prototype (Rediniotis et al. [60]).

been broadly explored in different articles in order to describe both TWSME and the interaction between plastic strains and phase transformations (Zhang et al. [88], Lim and McDowell [42], Hebda and White [30], Zhang et al. [88], Goo and Lexcellent [27], Prader and Kneissl [58], Fischer et al. [20], Bo and Lagoudas [11], Dobovsek [16], Govindjee and Hall [28], Zhang and McCormick [86, 87], Lexcellent et al. [40], Miller and Lagoudas [48], Savi et al. [66], Kumar et al. [35]). The loss of actuation due to repeated cycling involving plasticity represents another point of interest related to the plastic strain effects on SMAs.

\section{Applications}

The remarkable properties of SMAs are attracting significant technological interest in several fields of sciences and engineering, from medical to aerospace applications. Machado and Savi $[45,46]$ and Machado [44] make a review of the most relevant SMA applications within orthodontics, medical, and engineering fields.

SMA biomedical applications have become successful due to the noninvasive characteristic of $S M A$ devices and also due to their excellent biocompatibility. SMAs are usually employed in surgical instruments, cardiovascular, orthopedic, and orthodontic devices, among other applications. Besides medical applications, SMAs are widely explored in most engineering fields. A limiting factor to the design of new applications is SMAs' slow rate of response-their main drawback. In the following paragraphs, some engineering applications are briefly discussed.

The use of SMAs in flexible intelligent structures has a great potential. Naval industry is one of the areas that are investing in the development of these materials. As an illustrative example, one can cite the development of a SMA multiactuated flexible hydrofoil prototype, which simulates fishtail swimming dynamics, through hydrodynamic propulsion study (Rediniotis et al. [60]). The SMA wires are externally actuated by an electrical heating source. Figure 3.1 presents a picture of the hydrofoil prototype in a water tunnel.

Naval industry also exploits SMA to design a hydrostatic robot (Vaidyanathan et al. [80]). It consists of three fluid-filled bladders with wooden circular disks inserted between them. Four SMA springs are longitudinally attached to these five elements. Due to its concept, the robot is not only able to bear high depth pressures, but also to contour and to overlap obstacles due to its waving motion (Figure 3.2). 


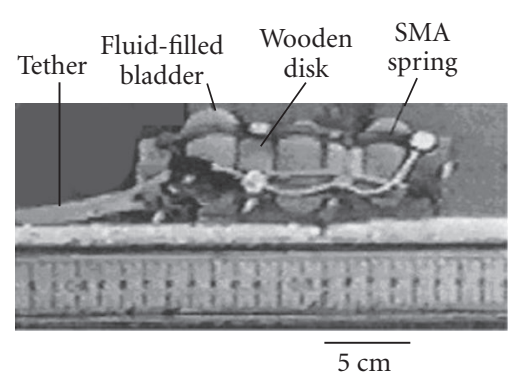

(a)
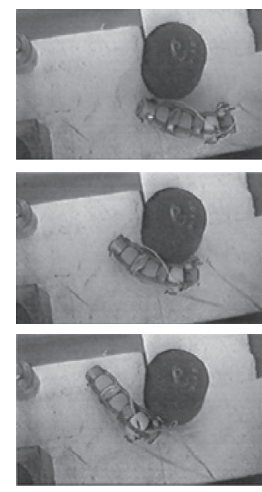

(b)

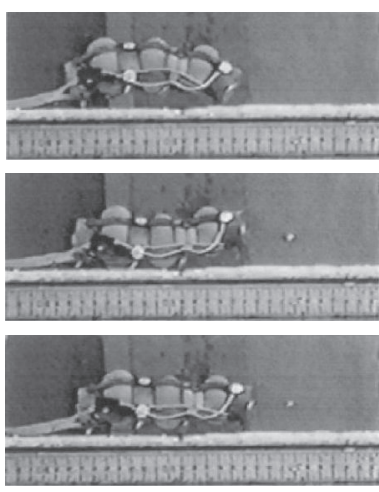

(c)

Figure 3.2. (a) $S M A$ actuated hydrostatic robot prototype under water; (b) $S M A$ actuated robot contouring an obstacle; (c) SMA actuated robot waving motion sequence (Vaidyanathan et al. [80]).

Vibration control is an important field within mechanical engineering, whose the main challenge is to attenuate primary system vibrations. SMAs are used for structures passive control due to their high damping capacity, which is related to their hysteretic behavior associated with the phase transformations the material undergoes. The great advantage concerning this type of behavior is that the higher the vibration amplitude is, the higher the damping is (van Humbeeck [81]). An alternative for vibration control is to use $S M A$ wires embedded in composite matrices that modify the mechanical properties of slender structures (Birman [10]; Rogers [62]).

A classical passive control device is known as tuned vibration absorber (TVA), which consists of a secondary oscillator coupled to the primary system. Adjusting the TVA's natural frequency to the primary system excitation frequency, it is possible to attenuate primary system vibrations. Williams et al. [84] present an adaptive TVA (ATVA) device using $S M A$ wires (Figure 3.3). This type of control is suitable for systems where frequencies vary or are unknown. SMA ATVAs are able to adjust their stiffness according to SMA wires temperature. This feature allows SMA ATVAs to attenuate primary system vibrations within a given frequency range.

A device successfully employed by the US Air Force in a F-14 chaser (used for the first time in the 1970s) motivates other interesting application of SMAs related to assemble pipes. This device is known as CryOfit, being developed by Raychem [59] (Figure 3.4). In order to assemble the two parts, the SMA coupling should be immersed in a liquid Nitrogen bath $\left(\cong-196^{\circ} \mathrm{C}\right)$. Afterwards, its diameter is mechanically enlarged and remains immersed in the Nitrogen bath. After being removed from bath, it is quickly assembled to the two pipes to be connected. As the SMA coupling returns to room temperature, it assumes its former shape, connecting the pipes. In some cases, the connection is better than the one obtained by welded joints, without the inconvenience of the inherent residual stress (Hodgson and Brown [31]). 


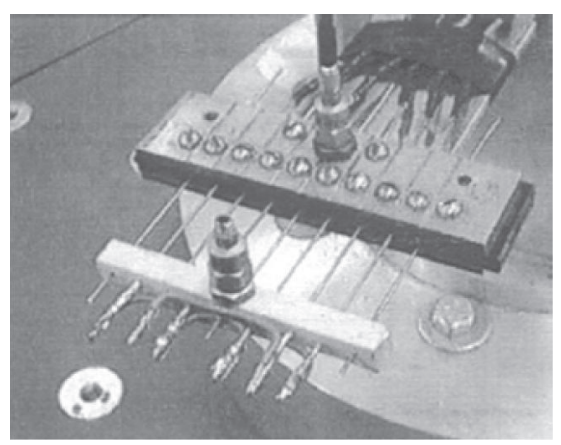

Figure 3.3. SMA adaptive tuned vibration absorber (Williams et al. 2002).
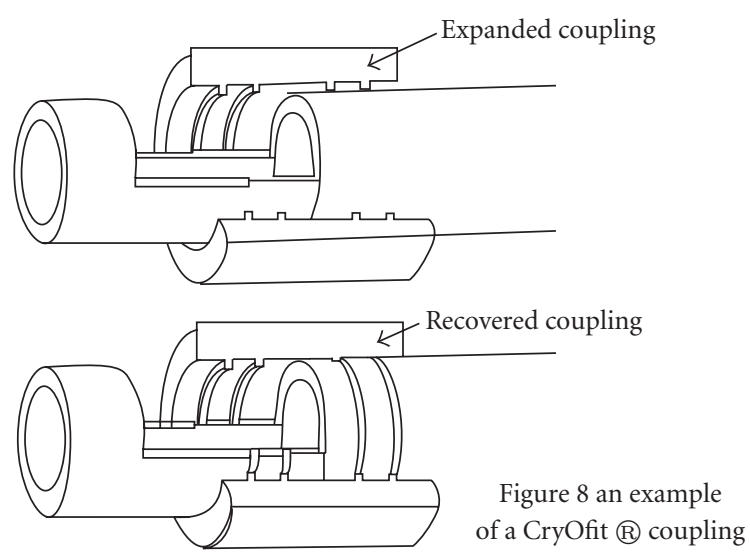

Figure 3.4. CryOfit SMA coupling (Hodgson and Brown [31]).

Another interesting application concerning coupling and joints can be often found in oil industry, where a SMA device is employed in pipe flanges (SINTEF [70]). A precompressed cylindrical SMA washer is placed between the flange and the nut, see Figure 3.5. When it is heated, it returns to its former shape and promotes an axial restitution force on the bolt, connecting the two parts. This procedure avoids the application of torques, which induces shear stress on the bolt. La Cava et al. [36] present modeling and simulations related to this device and conclude that this form of assembling offers about twenty percent of stress reduction on the bolt as compared to the traditional procedure.

SMAs are also used as actuators in microelectromechanical systems. For instance, Figure 3.6(a) shows an SMA oscillator that can be used as a position micro-controller. Basically, it involves a mass and two SMA springs attached to the mass, which can be 


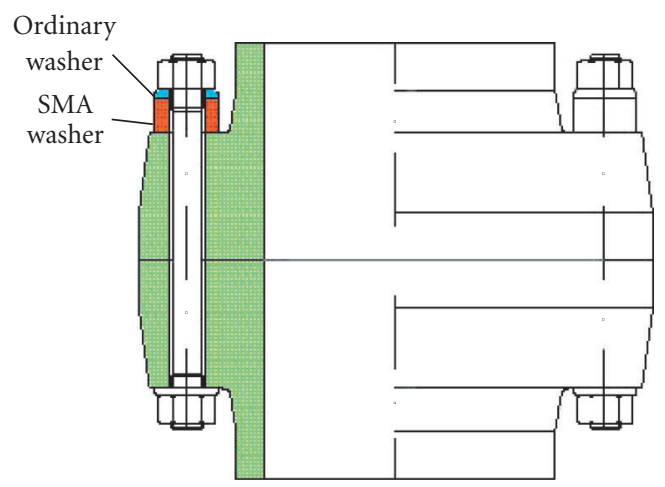

Figure 3.5. SMA preloading device (SINTEF, 2002).

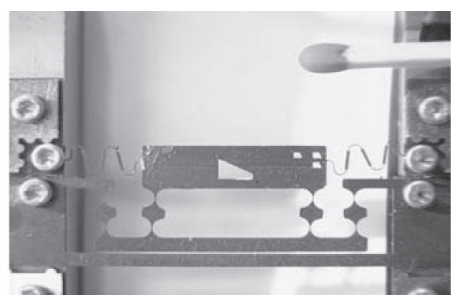

(a)

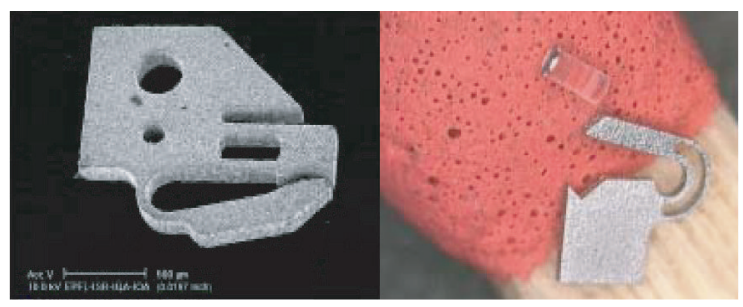

(b)

Figure 3.6. (a) Micro-oscillator prototype in comparison with a matchstick; (b) SMA micro-claw.

connected to a more complex system. The springs are precompressed assembled in their martensitic state. When the left SMA spring is heated, the system moves rightward. On the contrary, when the right SMA spring is heated, it recovers its former shape and brings the system to the neutral position. Figure 3.6(b) also shows a device related to microsystems, a microclaw that helps optical systems assembly. Based on TWSME, it is used to tweeze micro-lens that can measure less than $0.35 \mathrm{~mm}$.

Robotics is another area where SMA applications find a great potential. Basically, it can be used as actuators, trying to mimic the muscles movement. As an example, a flexible claw is presented in Figure 3.7 (Choi et al. [14]), which consists of two flexible beams connected to a gripper base. Each beam is connected to two springs. An SMA spring is used as an actuator, while a conventional spring is responsible for the beam position restoring. There is also a coil spring linking the two beams' free edges. Strain gages are responsible for monitoring the beams deflection. The SMA springs should be externally actuated. 


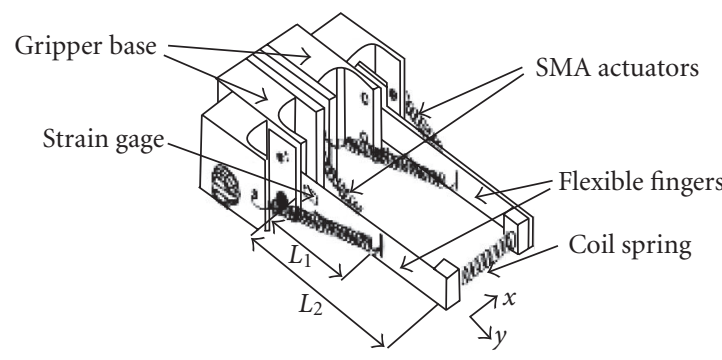

(a)

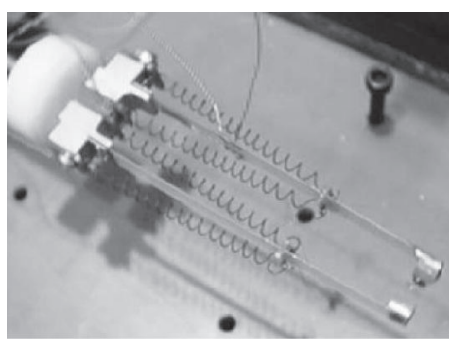

(b)

Figure 3.7. (a) $S M A$ actuated claw schematic representation; (b) SMA actuated claw prototype (Choi et al. [14]).

\section{Polynomial model}

The polynomial model proposed by Falk and coworkers is based on Devonshire's theory and considers a polynomial-free energy. Initially proposed for a one-dimensional media by Falk $[17,18]$, it was later extended for a three-dimensional context (Falk and Konopka [19]). According to this model, neither internal variables nor dissipation potential is necessary to describe pseudoelasticity and SME. Thus, the only state variables for this model are strain $\varepsilon$ and temperature $T$.

The form of the free energy is chosen in such a way that the minima and maxima points represent stability and instability of each phase of the SMA. As usual, in onedimensional models proposed for SMAs (Savi and Braga [64]), three phases are considered: austenite $(A)$ and two variants of martensite $(M+, M-)$. Hence, the free energy is chosen such that for high temperatures, it has only one minimum at vanishing strain, representing the equilibrium of the austenitic phase. At low temperatures, martensite is stable, and the free energy must have two minima at nonvanishing strains. At intermediate temperatures, the free energy must have equilibrium points corresponding to both phases.

Therefore, the free energy is defined as a sixth-order polynomial equation in a way that the minima and maxima points represent stability and instability of each phase of the SMA. Three phases are considered: austenite $(A)$ and two variants of martensite $(M+, M-)$. Hence, the form of the free energy is chosen such that for high temperatures $\left(T>T_{A}\right)$, it has only one minimum at vanishing strain, representing the equilibrium of the austenitic phase. For intermediate temperatures $\left(T_{M}<T<T_{A}\right)$, there are three minima corresponding to three stable phases-austenite $(A)$, and detwinned martensite induced by tension $(M+)$ and by compression $(M-)$. Lastly, at low temperatures $\left(T<T_{M}\right)$, martensite is stable, and the free energy must have two minima at nonvanishing strains. Therefore, the following free energy potential is defined:

$$
W(\varepsilon, T)=\frac{a}{2}\left(T-T_{M}\right) \varepsilon^{2}-\frac{b}{4} \varepsilon^{4}+\frac{b^{2}}{24 a\left(T_{A}-T_{M}\right)} \varepsilon^{6},
$$




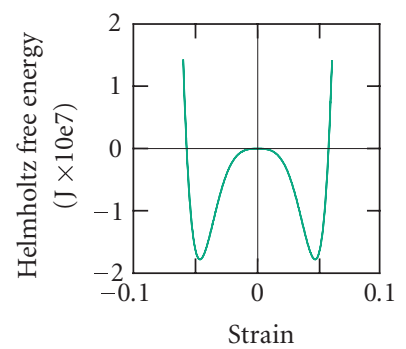

(a) $(T=283 \mathrm{~K})<T_{M}$

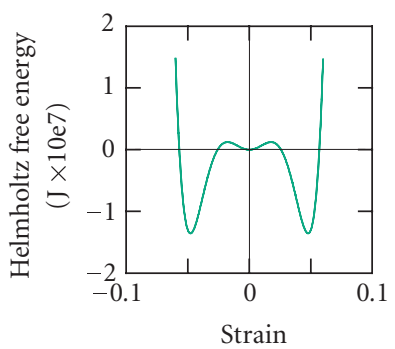

(b) $T_{M}<(T=298 \mathrm{~K})<T_{A}$

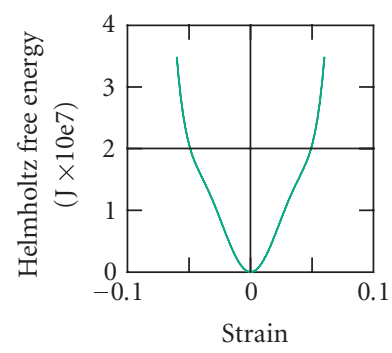

(c) $(T=323 \mathrm{~K})>T_{A}$

Figure 4.1. Free energy versus strain curves for Falk's model.

where $a$ and $b$ are positive material constants, $T_{A}$ is the temperature above which austenite is stable and $T_{M}$ is the temperature below which martensite is stable. Thus, the constitutive equation is given by

$$
\sigma=\frac{\partial W}{\partial \varepsilon}=a\left(T-T_{M}\right) \varepsilon-b \varepsilon^{3}+\frac{b^{2}}{4 a\left(T_{A}-T_{M}\right)} \varepsilon^{5} .
$$

To analyze the results given by Falk's polynomial model, qualitative tests at different temperatures are carried out using the following properties: $a=1 \times 10^{3} \mathrm{MPa} / \mathrm{K} ; b=$ $40 \times 10^{6} \mathrm{MPa} / \mathrm{K} ; T_{M}=287 \mathrm{~K} ; T_{A}=313 \mathrm{~K}$. Numerical simulations for prescribed stresses are solved using the Newton-Raphson method. Figure 4.1 shows free energy versus strain curves for three different temperatures. The extreme points define the different stable phases. Figure 4.2 shows stress-strain curves for the same three temperatures above. Figures 4.2(a) and 4.2(b) illustrate the martensite detwinning processes $(M+\rightarrow M-$ and $M-\rightarrow M+$ ), while Figure 4.2(c) shows the pseudoelastic effect.

The great advantage of Falk's polynomial model relies on its simplicity. This model represents in a qualitatively coherent way both martensite detwinning process and pseudoelasticity, although it does not consider twinned martensite $(M)$. In other words, there is no stable phase for $T<T_{M}$ in a stress-free state. 


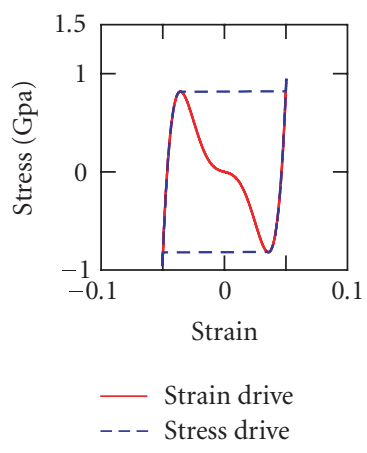

(a) $(T=283 \mathrm{~K})<T_{M}$

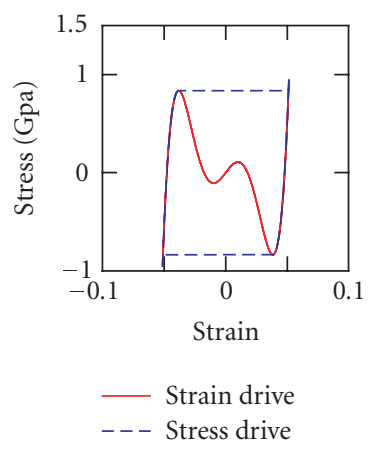

(b) $T_{M}<(T=298 \mathrm{~K})<T_{A}$

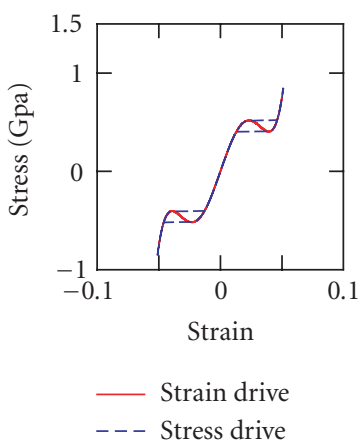

(c) $(T=323 \mathrm{~K})>T_{A}$

Figure 4.2. Stress-strain curves for Falk's model.

\section{Models with assumed phase transformation kinetics}

Models with assumed phase transformation kinetics consider, besides strain $(\varepsilon)$ and temperature $(T)$, an internal variable $(\beta)$, used to represent the martensitic volumetric fraction involved. The constitutive relation between stress and state variables, for SMA modeling, is considered in the rate form as follows:

$$
\dot{\sigma}=E \dot{\varepsilon}-\alpha \dot{\beta}-\Omega \dot{T},
$$

where Erepresents the elastic tensor, $\alpha$ corresponds to the phase transformation tensor, and $\Omega$ is associated with the thermoelastic tensor. Due to martensitic transformation nondiffusive nature, the martensitic volumetric fraction can be expressed as function of current values of stress and temperature $\beta=\beta(\sigma, T)$. Several authors propose different functions to describe the volumetric fraction evolution. Some of them will be discussed from here on.

The model firstly developed by Tanaka and coworkers (Tanaka and Nagaki [78], Tanaka [77]) was originally conceived to describe three-dimensional problems involving SMAs. Nevertheless, its implementation became restricted to the one-dimensional context. The authors consider exponential functions to describe phase transformations. Thus, for $A \Rightarrow M$ transformation, consider the following function:

$$
\beta=1-\exp \left[-a_{M}\left(M_{s}-T\right)-b_{M} \sigma\right]+\beta_{0},
$$

where $a_{M}$ and $b_{M}$ are positive material parameters, $M_{s}$ is the martensite formation start temperature, and $\beta_{0}$ represents the volumetric fraction when phase transformation takes place. The critical stress for martensitic phase transformation $(A \Rightarrow M+)$ beginning is given by $\sigma_{M_{S}} \geq a_{M} / b_{M}\left(T-M_{s}\right)$. Since an exponential function is adopted, there should be an extra consideration for the phase transformation final bounds. When $\beta=0.99$, the transformation is considered complete. For the reverse transformation $(M+\Rightarrow A)$ there 
is another exponential function as follows:

$$
\beta=\beta_{0} \exp \left[-a_{A}\left(T-A_{s}\right)-b_{A} \sigma\right]
$$

where $a_{A}$ and $b_{A}$ are positive material constants and $A_{s}$ is the austenite formation start temperature. Equation (5.3) applies for stress values such as $\sigma_{A_{S}} \leq a_{A} / b_{A}\left(T-A_{s}\right)$. An analogous procedure is taken for the reverse transformation final bounds determination.

Boyd and Lagoudas [12] rewrite Tanaka's original model, for a three-dimensional theory construction. For the sake of comparison, the model was here reduced to one-dimensional context. Under this assumption, the relations used to describe phase transformation evolution remain the same as in Tanaka's model, despite the definitions adopted for the constants $a_{M}, b_{M}, a_{A}$, and $b_{A}$ that are estimated as follows:

$$
a_{M}=\frac{2 \ln (10)}{M_{s}-M_{f}}, \quad b_{M}=\frac{a_{M}}{C_{M}}, \quad a_{A}=\frac{2 \ln (10)}{A_{f}-A_{s}}, \quad b_{A}=\frac{a_{A}}{C_{A}} .
$$

Liang and Rogers [41] present an alternative evolution law for the volumetric fraction based on cosine functions. Hence, the volumetric fraction evolution equation for the martensitic transformation $(A \Rightarrow M+)$ is given by:

$$
\beta=\frac{1-\beta_{0}}{2} \cos \left[A_{M}\left(T-M_{f}-\frac{\sigma}{C_{M}}\right)\right]+\frac{1+\beta_{0}}{2}
$$

and holds for $C_{M}\left(T-M_{s}\right)<\sigma<C_{M}\left(T-M_{f}\right)$, where $C_{M}$ is a material parameter, $M_{f}$ corresponds to the martensite formation finish temperature, and the coefficient $A_{M}$ is defined by (5.7).

For the reverse transformation $(M+\Rightarrow A)$, the equation is given by

$$
\beta=\frac{\beta_{0}}{2}\left\{\cos \left[A_{A}\left(T-A_{s}-\frac{\sigma}{C_{A}}\right)\right]+1\right\}
$$

and takes place when $C_{A}\left(T-A_{f}\right)<\sigma<C_{A}\left(T-A_{s}\right)$.

Analogously, $C_{A}$ is a material parameter, $A_{s}$ represents the austenite formation start temperature, and $A_{A}$ is defined according to (5.7),

$$
A_{M}=\frac{\pi}{M_{s}-M_{f}} ; \quad A_{A}=\frac{\pi}{A_{f}-A_{s}} .
$$

The above-presented model was applied to acoustic vibration control studies and its results show good agreement with experimental data (Rogers et al. [63]; Anders et al. [4]). The authors also developed a three-dimensional model, in which they suggest that phase transformations are driven by the associated distortion energy.

Brinson [13] offers an alternative approach to the phase transformation kinetics, in which, besides considering cosine functions, the internal variable $\beta$ is split into two distinct martensitic fractions-one temperature induced $\beta_{T}$, and the other stress induced $\beta_{S}$, in such a way that $\beta=\beta_{T}+\beta_{S}$. The author also considers different elastic moduli for austenite $E_{A}$ and martensite $E_{M}$, so that the elastic modulus is given by a linear combination such that: $E(\beta)=E_{A}+\beta\left(E_{M}-E_{A}\right)$. 
The martensitic transformation evolution is expressed by

$$
\begin{gathered}
\beta_{S}=\frac{1-\beta_{S_{0}}}{2} \cos \left\{\frac{\pi}{\sigma_{S}^{\mathrm{CRIT}}-\sigma_{f}^{\mathrm{CRIT}}}\left[\sigma-\sigma_{f}^{\mathrm{CRIT}}-C_{M}\left(T-M_{S}\right)\right]\right\}+\frac{1+\beta_{s_{0}}}{2}, \\
\beta_{T}=\beta_{T_{0}}-\frac{\beta_{T_{0}}}{1-\beta_{S_{0}}}\left(\beta_{S}-\beta_{S_{0}}\right),
\end{gathered}
$$

both (5.8) hold for $\sigma_{s}^{\mathrm{CRIT}}+C_{M}\left(T-M_{s}\right)<\sigma<\sigma_{f}^{\mathrm{CRIT}}+C_{M}\left(T-M_{s}\right)$ and $T>M_{s}$.

For $T<M_{s}$ and $\sigma_{s}^{\text {CRIT }}<\sigma<\sigma_{f}^{\text {CRIT }}$, the martensitic transformation is given by

$$
\begin{gathered}
\beta_{s}=\frac{1-\beta_{s_{0}}}{2} \cos \left[\frac{\pi}{\sigma_{s}^{\mathrm{CRIT}}-\sigma_{f}^{\mathrm{CRIT}}}\left(\sigma-\sigma_{f}^{\mathrm{CRIT}}\right)\right]+\frac{1+\beta_{s_{0}}}{2}, \\
\beta_{T}=\beta_{T_{0}}-\frac{\beta_{T_{0}}}{1-\beta_{S_{0}}}\left(\beta_{S}-\beta_{S_{0}}\right)+\triangle_{T}
\end{gathered}
$$

where

$$
\triangle_{T}= \begin{cases}\frac{1-\beta_{T_{0}}}{2}\left\{\cos \left[a_{M}\left(T-M_{f}\right)\right]+1\right\} & \text { if } M_{f}<T<M_{s}, T<T_{0} \\ \text { else } & 0 .\end{cases}
$$

The reverse transformation holds for $C_{A}\left(T-A_{s}\right)<\sigma<C_{A}\left(T-A_{s}\right)$ and $T>A_{s}$ and is defined as

$$
\begin{aligned}
& \beta_{S}=\frac{\beta_{S_{0}}}{2}\left\{\cos \left[a_{A}\left(T-A_{S}-\frac{\sigma}{C_{A}}\right)\right]+1\right\}, \\
& \beta_{T}=\frac{\beta_{T_{0}}}{2}\left\{\cos \left[a_{A}\left(T-A_{S}-\frac{\sigma}{C_{A}}\right)\right]+1\right\},
\end{aligned}
$$

where the coefficients $a_{M}$ and $a_{A}$ are the same as those given by (5.7). $\beta_{s_{0}}$ and $\beta_{T_{0}}$ represent, respectively, the stress-induced and the temperature-induced martensitic volumetric fractions immediately before transformations begin.

5.1. Numerical simulations for models with assumed transformation kinetics. $\mathrm{Nu}-$ merical simulations for the models previously discussed are carried out for the stress driving case. Qualitative results are provided for a Nitinol alloy, whose properties are listed in Table 5.1 (Brinson [13]).

Figures 5.1(a), 5.1(b), and 5.1(c) compare stress-strain curves given by the models proposed by Tanaka and Nagaki, Liang and Rogers and Brinson at different temperatures, since the results obtained for Boyd and Lagoudas model for one-dimensional case are exactly the same as those found for Tanaka's model. All models are able to describe pseudoelasticity, however, a relevant discrepancy in the critical stress for martensitic transformation compared to Brinson's model is noticeable. Another difference is noticed in the product phase elastic modulus, since Brinson considers different material properties for each phase. This feature can be easily incorporated to the other models. It is worthwhile 
An overview of constitutive models for shape memory alloys

Table 5.1. Thermomechanical material properties for Nitinol alloy (Brinson [13]).

\begin{tabular}{l|c|c}
\hline $\begin{array}{l}\text { Material } \\
\text { properties }\end{array}$ & $\begin{array}{c}\text { Transformation } \\
\text { temperatures }\end{array}$ & $\begin{array}{c}\text { Model } \\
\text { parameters }\end{array}$ \\
\hline$E_{A}=67 \times 10^{3} \mathrm{MPa}$ & $M_{f}=282 \mathrm{~K}$ & $C_{M}=8 \mathrm{MPa} / \mathrm{K}$ \\
$E_{M}=26.3 \times 10^{3} \mathrm{MPa}$ & $M_{s}=291.4 \mathrm{~K}$ & $C_{A}=13.8 \mathrm{MPa} / \mathrm{K}$ \\
$\Omega=0.55 \mathrm{MPa} / \mathrm{K}$ & $A_{s}=307.5 \mathrm{~K}$ & $\sigma_{S}^{\text {CRIT }}=100 \mathrm{MPa}$ \\
$\varepsilon_{R}=0.067$ & $A_{f}=322 \mathrm{~K}$ & $\sigma_{f}^{\text {CRIT }}=170 \mathrm{MPa}$ \\
\hline
\end{tabular}

to observe that only Brinson's model is able to correctly describe the reorientation process $(M \Rightarrow M+)$ for temperatures below $M_{s}$, since the other models have no stable phase for $T<M_{s}$ in a stress-free state, in other words, they do not consider the twinned martensite, see Figure 5.3(c).

Figure 5.2(a) shows the stress-strain-temperature diagram provided by Brinson's model for the thermomechanical loading presented in Figure 5.2(b). During mechanical cycles, it is possible to identify internal subloops due to incomplete phase transformations. After complete mechanical unloading $(t=16 \mathrm{~s})$, some residual strain is still observed. This residual strain can be fully recovered by heating the sample above $A_{f}$, attesting the model's ability to describe SME. Figure 5.2(c) shows the volumetric fractions evolution. In this case, the internal variable responsible for phase transformation is $\beta_{S}$. Thus, analogous results can be achieved for the other models (only for temperatures above $M_{s}$ ).

Phase transformation phenomenon due to temperature variation for Brinson's model is represented in Figure 5.3(a) for a stress-free state. Again, different material properties for austenite and martensite are verified for the linear regions, which correspond to the thermal expansion phenomenon. This result also confirms the model's ability to describe internal subloops even during $M \Rightarrow A$ and $A \Rightarrow M$ transformations. Figure 5.3(b) presents the associated thermomechanical loading, while Figure 5.3(c) shows the volumetric fractions evolution. Note that, in this case, the internal variable $\beta_{T}$ is responsible for phase transformation. Since the other models do not take this volumetric fraction into account, they are not able to describe this phenomenon.

Experimental studies (Funakubo [24]) reveal that phase transformations are strongly dependent on loading history. Thus, the critical stresses for phase transformation are modified under cyclic loading. Usually, critical stress is reduced for martensitic transformation, while it is increased for reverse transformation, inducing loop height reduction. The models with assumed transformation kinetics are not able to capture this feature, since they have fixed critical stress limits (only temperature dependent). Tanaka et al. [79] introduce some changes to the original model, which allow for critical stress sensitivity description during subloop tests.

This class of models can describe compressive behavior by considering the martensitic volumetric fraction within the interval $-1 \leq \beta \leq+1$ (Pacheco and Savi [55]), where negative values of $\beta$ are related to compressive behavior. Besides, it is necessary to consider the stress modulus and to replace the $\sigma$ stress by sign $(\sigma)=\sigma /|\sigma|$ in the evolution equations and their respective limits. 


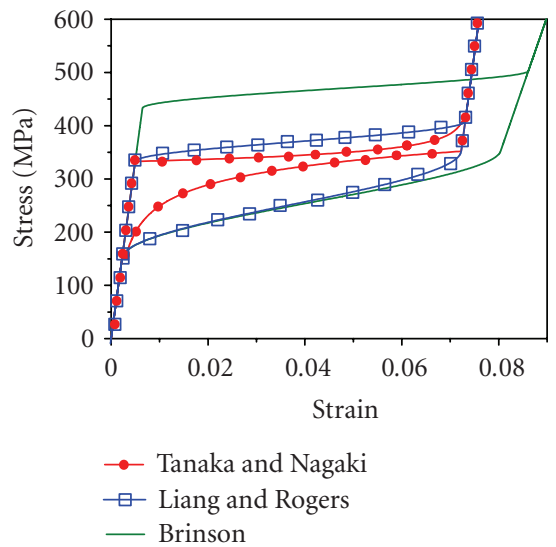

(a) $(T=333 \mathrm{~K})>A_{f}$

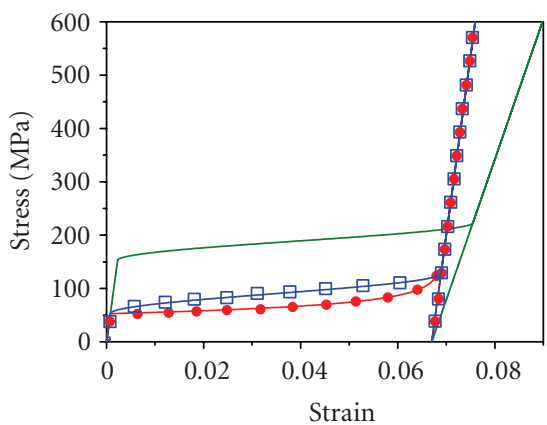

$\rightarrow$ Tanaka and Nagaki

—— Liang and Rogers

- Brinson

(b) $M_{S}<(T=298 \mathrm{~K})<A_{S}$

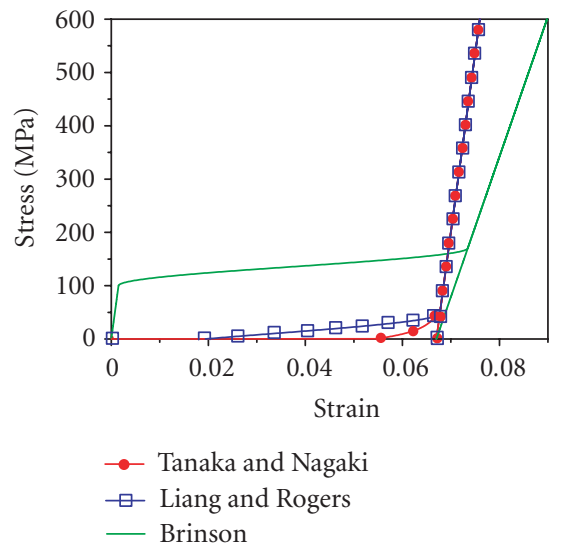

(c) $(T=288 \mathrm{~K})<M_{S}$

Figure 5.1. Stress-strain curves for models with assumed transformation kinetics.

\section{Models with internal constraints}

Fremond $[22,23]$ originally proposed a three-dimensional model considering three volumetric fractions. The first is associated with austenite $(A)$, and the two others represent detwinned martensite variants, which for the one-dimensional case can be interpreted as induced by tension $(M+)$ and by compression $(M-)$. In its formulation, Fremond's model assumes a free energy potential for each phase as a function of strain $(\varepsilon)$ and temperature $(T)$. The global free energy $(\psi)$ is given by a balanced summation of the partial free energies, where the weights correspond to the volumetric fraction of each phase. Therefore, three internal variables are included in the model. 
16 An overview of constitutive models for shape memory alloys

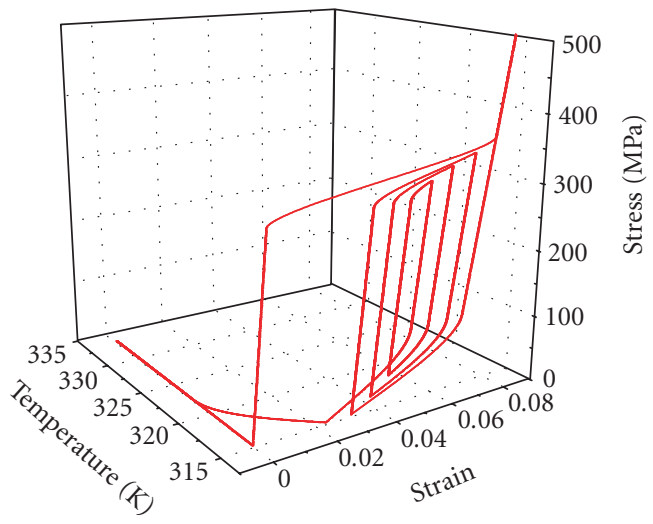

(a)

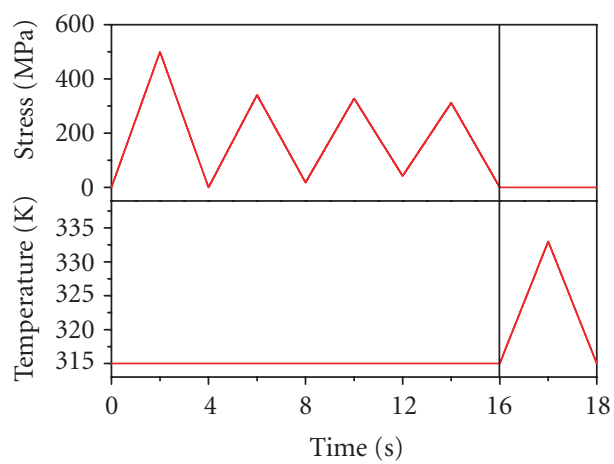

(b)

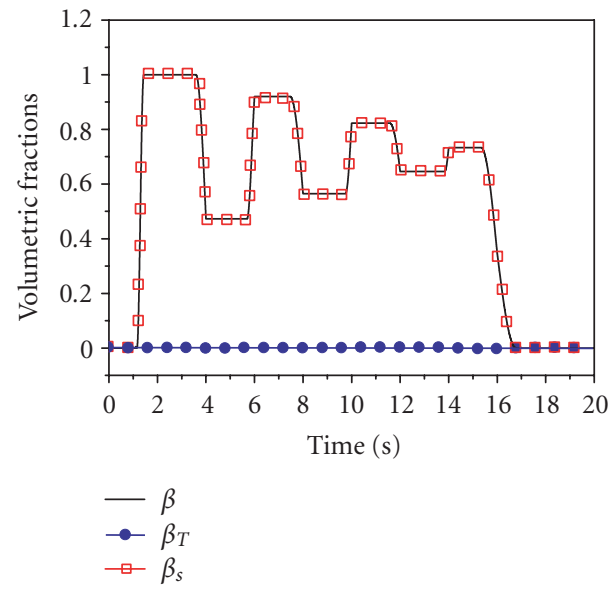

(c)

Figure 5.2. SME and mechanical internal subloops for Brinson's model: (a) stress-strain-temperature diagram; (b) thermomechanical loading; (c) volumetric fractions evolution. 


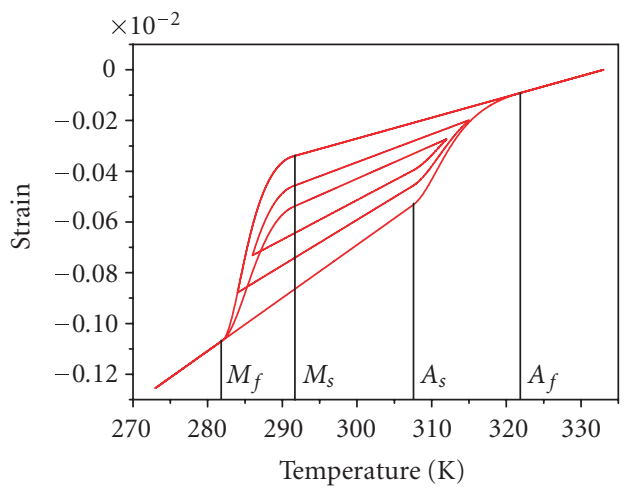

(a)

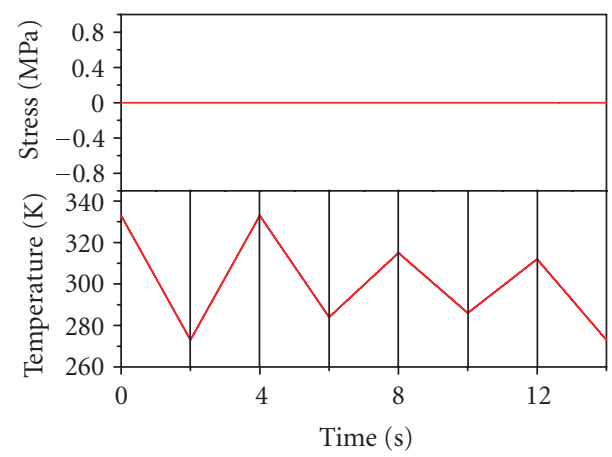

(b)

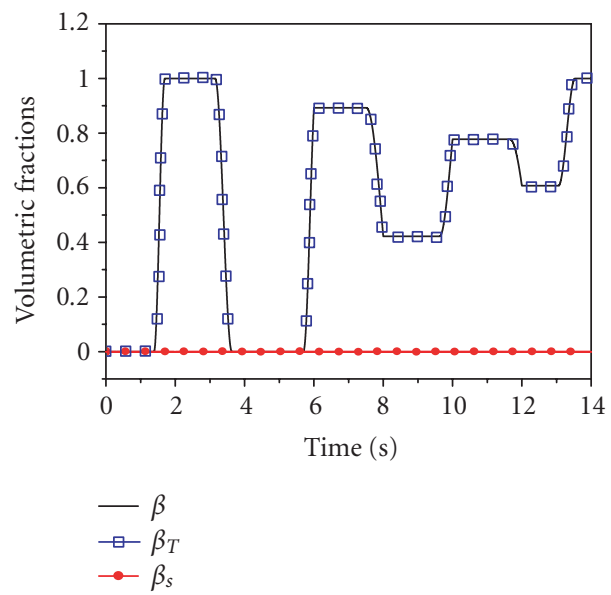

(c)

Figure 5.3. Phase transformation due to temperature variation and thermal internal subloops for Brinson's model. (a) Strain-temperature diagram; (b) thermomechanical loading; (c) volumetric fractions evolution. 
Savi and Braga [64] discuss some characteristics related to the original Fremond's model. Afterwards, a new one-dimensional model, built upon the original Fremond's model, is developed and reported in different references (Savi et al. [66], Baêta-Neves et al. [8], Paiva et al. [56], Savi and Paiva [65]). This new model considers different material properties and a new volumetric fraction associated with twinned martensite $(M)$ that helps the correct description of the phase transformation phenomenon due to temperature variation. The model also considers the plastic strains effect and plastic-phase transformation coupling, which makes possible TWSME description (Savi et al. [66]). Moreover, a modification promotes the horizontal enlargement of the stress-strain hysteresis loop that leads to better adjustments with respect to experimental data (BaetaNeves et al. [8]). Recently, tensile-compressive asymmetry and internal subloops due to incomplete phase transformation have been included in the model (Paiva et al. [56], Savi and Paiva [65]).

The present contribution focuses on this modified model and, since both plasticity and tensile-compressive asymmetry are out of this work's scope, for the sake of simplicity, the formulation presented herein does not consider such phenomena. For more information about the complete model, see Paiva et al. [56].

The formulation of the model considers, besides elastic strain $\left(\varepsilon_{e}\right)$ and temperature $(T)$, four more state variables associated with the volumetric fraction of each phase: $\beta_{1}$ is associated with tensile detwinned martensite, $\beta_{2}$ is related to compressive detwinned martensite, $\beta_{3}$ represents austenite, and $\beta_{4}$ corresponds to twinned martensite. A free energy potential is proposed by considering each isolated phase. After this definition, a free energy of the mixture can be written by weighting each energy function with its volumetric fraction. Since $\beta_{1}+\beta_{2}+\beta_{3}+\beta_{4}=1$, it is possible to rewrite the free energy of the mixture as a function of three volumetric fractions: $\beta_{n}(n=1,2,3)$. After this, an additive decomposition where the elastic strain may be written as $\varepsilon_{e}=\varepsilon-\alpha_{h}\left(\beta_{1}-\beta_{2}\right)$ is assumed. Parameter $\alpha_{h}$ is introduced in order to define the horizontal width of the stressstrain hysteresis loop. Finally, a pseudo-potential of dissipation is defined as a function of the rates $\dot{\varepsilon}, \dot{T}$ and $\dot{\beta}_{n}$. By employing the standard generalized material approach (Lemaitre and Chaboche [38]), it is possible to obtain a complete set of constitutive equations that describes the thermomechanical behavior of SMAs, as presented below:

$$
\begin{gathered}
\sigma=E\left[\varepsilon+\alpha_{h}\left(\beta_{2}-\beta_{1}\right)\right]+\alpha\left(\beta_{2}-\beta_{1}\right)-\Omega\left(T-T_{0}\right) \\
\dot{\beta_{1}}=\frac{1}{\eta}\left\{\alpha \varepsilon+\Lambda(T)+\left(2 \alpha \alpha_{h}+E \alpha_{h}^{2}\right)\left(\beta_{2}-\beta_{1}\right)+\alpha_{h}\left[E \varepsilon-\Omega\left(T-T_{0}\right)\right]-\partial_{\beta_{1}} \mathbf{J}_{\pi}\right\}+\partial_{\dot{\beta}_{1}} \mathbf{J}_{\chi} \\
\dot{\beta_{2}}=\frac{1}{\eta}\left\{-\alpha \varepsilon+\Lambda(T)-\left(2 \alpha \alpha_{h}+E \alpha_{h}^{2}\right)\left(\beta_{2}-\beta_{1}\right)-\alpha_{h}\left[E \varepsilon-\Omega\left(T-T_{0}\right)\right]-\partial_{\beta_{2}} \mathbf{J}_{\pi}\right\}+\partial_{\dot{\beta}_{2}} \mathbf{J}_{\chi} \\
\dot{\beta_{3}}=\frac{1}{\eta}\left\{-\frac{1}{2}\left(E_{A}-E_{M}\right)\left[\varepsilon+\alpha_{h}\left(\beta_{2}-\beta_{1}\right)\right]^{2}+\Lambda_{3}(T)\right. \\
\left.+\left(\Omega_{A} \Omega_{M}\right)\left(T-T_{0}\right)\left[\varepsilon+\alpha_{h}\left(\beta_{2}-\beta_{1}\right)\right]-\partial_{\beta_{3}} \mathbf{J}_{\pi}\right\}+\partial_{\beta_{3}} \mathbf{J}_{\chi}
\end{gathered}
$$


where $E=E_{M}+\beta_{3}\left(E_{A}-E_{M}\right)$ is the elastic modulus, while $\Omega=\Omega_{M}+\beta_{3}\left(\Omega_{A}-\Omega_{M}\right)$ is related to the thermal expansion coefficient. $T_{0}$ is a reference temperature when $\varepsilon=0$. Moreover, it should be pointed out that subscript $A$ refers to austenitic phase, while $M$ refers to martensite.

The terms $\partial_{\beta_{n}} \mathbf{J}_{\pi}$ (for $n=1,2,3$ ) are the subdifferentials of the indicator function $\mathbf{J}_{\pi}$ with respect to $\beta_{n}$ (Rockafellar [61]). The indicator function $\mathbf{J}_{\pi}\left(\beta_{1}, \beta_{2}, \beta_{3}\right)$ is related to the following convex set $\pi$, which provides the internal constraints related to the phases' coexistence:

$$
\pi=\left\{\beta_{n} \in \mathfrak{R} \mid 0 \leq \beta_{n} \leq 1 ; \beta_{1}+\beta_{2}+\beta_{3} \leq 1\right\}
$$

so that

$$
\mathbf{J}_{\pi}\left(\beta_{n}\right)= \begin{cases}0 & \text { if } \beta_{n} \in \pi \\ \infty & \text { if } \beta_{n} \notin \pi\end{cases}
$$

With respect to evolution equations of volumetric fractions (6.2)-(6.4), $\eta$ is the dissipation coefficient and $\mathbf{J}_{\chi}\left(\dot{\varepsilon}, \dot{T}, \dot{\beta_{1}}, \dot{\beta_{2}}, \dot{\beta_{3}}\right)$ is the indicator function related to the convex set $\chi$. This indicator function establishes conditions for the correct description of internal subloops due to incomplete phase transformations and also to eliminate the phase transformations $M+\Rightarrow M$ or $M-\Rightarrow M$. Hence, the convex set $\chi$ may be written as follows for a mechanical loading history with $\dot{\sigma} \neq 0$ :

$$
\chi=\left\{\begin{array}{l|l}
\dot{\varepsilon_{n}} \in \mathfrak{R} & \begin{array}{l}
\dot{\varepsilon} \beta_{1} \geq 0 ; \dot{\varepsilon} \dot{\beta_{3}} \leq 0 \text { if } \varepsilon_{0}>0 \\
\dot{\varepsilon} \dot{\beta}_{2} \leq 0 ; \dot{\varepsilon} \dot{\beta}_{3} \geq 0 \text { if } \varepsilon_{0}<0
\end{array}
\end{array}\right\},
$$

where

$$
\varepsilon_{0}=\varepsilon-\frac{\Omega}{E}\left(T-T_{0}\right)
$$

On the other hand, when $\dot{\sigma}=0$, the convex set $\chi$ is expressed by

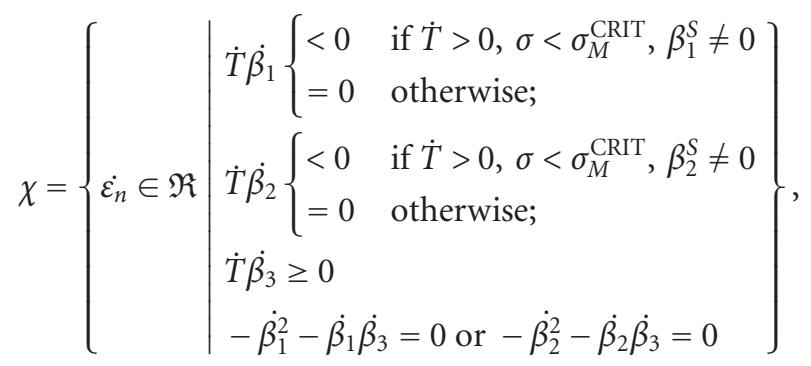

where $\beta_{1}^{S}$ and $\beta_{2}^{S}$ are the values of $\beta_{1}$ and $\beta_{2}$, respectively, when the phase transformation begins to take place. Moreover, $\sigma_{M}^{\mathrm{CRIT}}$ is the critical stress value for both $M \Rightarrow M+$ and $M \Rightarrow M-$ phase transformations. 
Now, it is important to consider the definition of the functions $\Lambda$ and $\Lambda_{3}$, which are temperature dependent as follows:

$$
\begin{gathered}
\Lambda=-L_{0}+\frac{L}{T_{M}}\left(T-T_{M}\right), \\
\Lambda_{3}=-L_{0}^{A}+\frac{L^{A}}{T_{M}}\left(T-T_{M}\right) .
\end{gathered}
$$

Here, $T_{M}$ is the temperature below which the martensitic phase becomes stable. Besides, $L_{0}, L, L_{0}^{A}$, and $L^{A}$ are parameters related to critical stress for phase transformation.

The definition of these functions establishes the phase transformation critical stress for each phase. Actually, the definition of critical stress is essential to evaluate the convex set $\chi$ when $\dot{\sigma}=0$. It may be obtained from (6.1)-(6.2) by assuming that $\dot{\beta_{1}}=\beta_{1}=\beta_{2}=\beta_{3}=0$. Therefore, the following expression is obtained:

$$
\sigma_{M}^{\mathrm{CRIT}}=\frac{E_{M}}{\alpha+E_{M} \alpha_{h}}\left[L_{0}-\frac{L\left(T-T_{M}\right)}{T_{M}}+\alpha_{h} \Omega_{M}\left(T-T_{0}\right)\right]-\Omega_{M}\left(T-T_{0}\right) .
$$

Another important characteristic of the model is that there is a critical temperature $T_{C}$ below which there is no change in stress-strain hysteresis loop position. This temperature limits the variation of the transformation critical stress and can be determined by evaluating again the two first constitutive equations, by assuming that $\dot{\beta}_{1}=\beta_{2}=\beta_{3}=0 ; \beta_{1}=1$; $T=T_{C}$, and $\varepsilon=\varepsilon_{R}\left(\varepsilon_{R}\right.$ being the maximum residual strain). With these assumptions, the following parameters are defined:

$$
\begin{gathered}
\alpha_{h}=\varepsilon_{R}-\frac{\alpha}{E_{M}}-\frac{\Omega_{M}}{E_{M}}\left(T_{C}-T_{0}\right), \\
T_{C}=T_{M}\left[\frac{L E_{M}+\alpha\left(\Omega_{M} T_{0}-\alpha\right)}{L E_{M}+\alpha \Omega_{M} T_{M}}\right] .
\end{gathered}
$$

Moreover, it is assumed that $\Lambda(T)$ does not vary for $T<T_{C}$. Besides, in order to differentiate forward phase transformation from reverse phase transformation, the internal dissipation parameter $\eta$ is subdivided into $\eta^{L}$ and $\eta^{U}$ associated to loading and unloading processes, respectively, as follows:

$$
\eta= \begin{cases}\eta^{L} & \text { if } \dot{\varepsilon}>0 \\ \eta^{U} & \text { if } \dot{\varepsilon}<0\end{cases}
$$

6.1. Numerical simulations for the model with internal constraints. The solution of the constitutive equations employs an implicit Euler method together with the operator split technique (Ortiz et al. [53]). For $\beta_{n}(n=1,2,3)$ calculation, the evolution equations are solved in a decoupled way. At first, the equations (except for the subdifferentials) are solved by using an iterative implicit Euler method. If the estimated results obtained for $\beta_{n}$ does not fit the imposed constraints, an orthogonal projection algorithm brings their value to the nearest point on the domain's surface. 


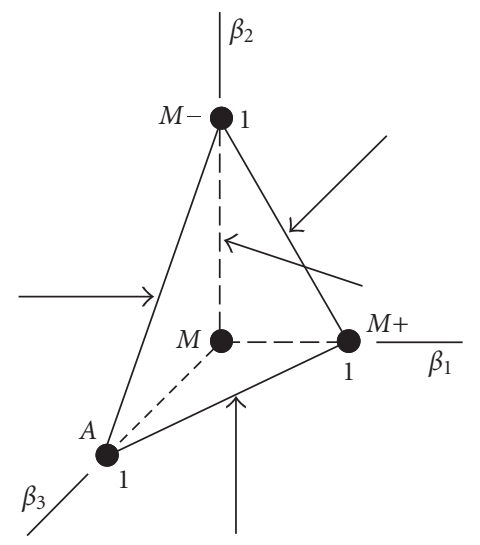

Figure 6.1. Orthogonal projection graphic representation.

Table 6.1. Parameters for the model with internal constraints.

\begin{tabular}{l|c|c|c}
\hline$E_{A}(\mathrm{GPa})$ & $E_{M}(\mathrm{GPa})$ & $\alpha(\mathrm{MPa})$ & $\varepsilon_{R}$ \\
67 & 26.3 & 89.42 & 0.067 \\
\hline$L_{0}$ & $L$ & $L_{0}^{A}$ & $L^{A}$ \\
0.15 & 41.5 & 0.15 & 253.5 \\
\hline$\Omega_{A}(\mathrm{MPa} / \mathrm{K})$ & $\Omega_{M}(\mathrm{MPa} / \mathrm{K})$ & $T_{M}(\mathrm{~K})$ & $T_{0}(\mathrm{~K})$ \\
0.55 & 0.55 & 291.4 & 298 \\
\hline- & $\eta^{L}(\mathrm{MPa} . \mathrm{s})$ & $\eta^{U}(\mathrm{MPa} . \mathrm{s})$ & - \\
& 1 & 2.7 & \\
\hline
\end{tabular}

For instance, the domain of the constraint related to the coexistence of the material phases, in other words $\beta_{1}+\beta_{2}+\beta_{3} \leq 1$, can be geometrically interpreted as the internal region (including the surface) of the tetrahedron shown in Figure 6.1. The orthogonal projections correspond to the subdifferentials. For stress driving simulations, another iterative method is necessary.

Numerical simulations are now carried out in order to show the potentialities of the discussed model to describe SMA behavior. The parameters shown in Table 6.1 are set based on the properties listed in Table 5.1 (Brinson [13]) and on typical Nitinol properties obtained in SMA-INC (2001).

Figure 6.2(a) shows the pseudoelastic effect for $T=333 \mathrm{~K}$, respecting the correspondent thermomechanical loading (Figure 6.2(b)). It is possible to note the difference between the austenitic and the martensitic elastic moduli. Figure 6.2(c) presents the four volumetric fractions evolution. First, the structure is fully austenite. When martensitic transformation takes place, both phases $A$ and $M+$ coexist. After it finishes, there is only tensile detwinned martensite. During reverse transformation, $M+$ and $A$ switch places as well, so that after this process is finished, austenite becomes stable again and no residual strain remains. 
22 An overview of constitutive models for shape memory alloys

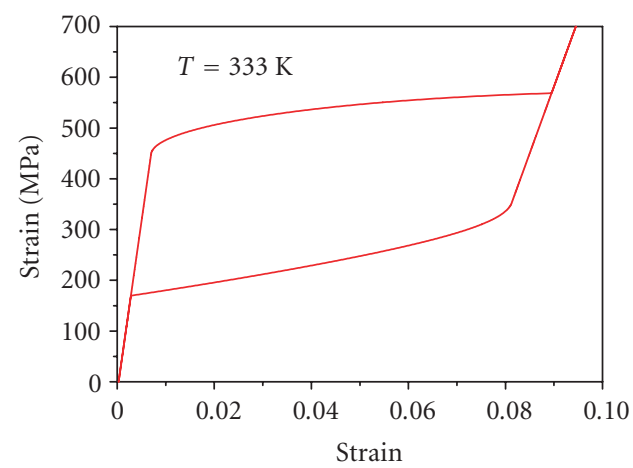

(a)

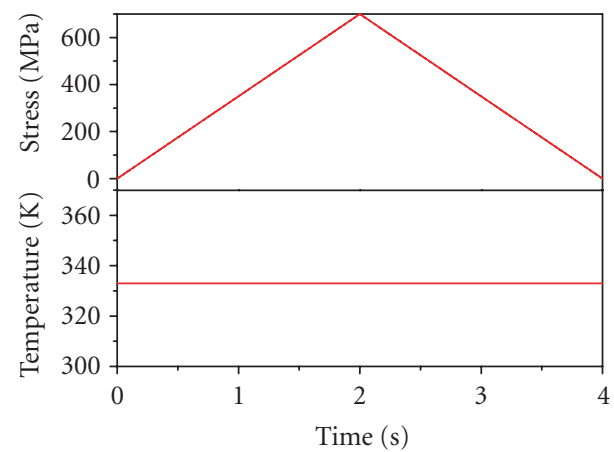

(b)

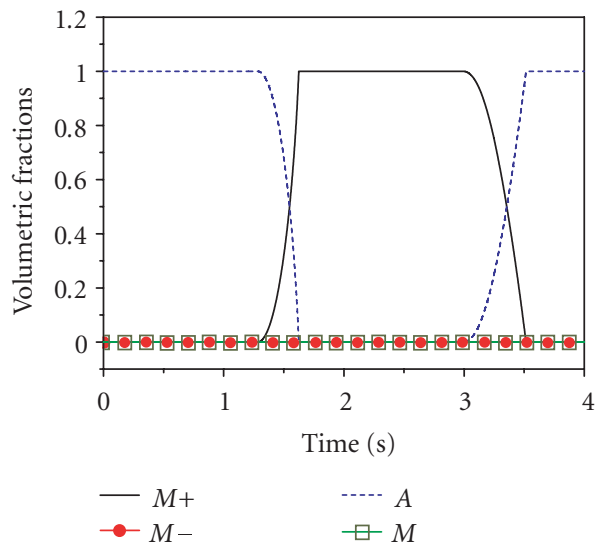

(c)

Figure 6.2. Pseudoelastic effect: (a) stress-strain diagram $T=333 \mathrm{~K}$; (b) thermomechanical loading; (c) volumetric fractions evolution. 
Figure 6.3(a) demonstrates the model ability to describe both $S M E$ and internal subloops due to incomplete phase transformations (Savi and Paiva [65]), according to the thermomechanical loading presented in Figure 6.3(b). The mechanical cyclic loading is applied at such a temperature that upon final unloading, there is still some residual strain, which can be fully recovered by heating the sample until austenite becomes stable and cooling back to test temperature. Figure 6.3(c) shows the volumetric fractions evolution. Initially, the structure is fully austenitic, until phase transformation $A \Rightarrow$ $M+$ takes place. After that, the structure is $100 \%$ tensile detwinned martensitic. The first reverse transformation partially converts $M+\Rightarrow A$. During the mechanical subloops, $M+$ and $A$ switch places, with linear regions that correspond to each intermediate cycle elastic behavior. The last phase transformation is associated with the thermal cycle, which is responsible for residual strain recovery. By cooling back the SMA specimen to the test temperature, no phase transformation occurs. The other two volumetric fractions $(M$ and $M-$ ) remain null.

Figure 6.4(a) presents the phase transformation phenomenon due to temperature variation together with internal subloops due to incomplete transformations, according to the thermomechanical loading shown in Figure 6.4(b). Again, different material properties are identified for austenite and martensite as seen in the linear regions (thermal expansion phenomenon). Figure 6.4(c) brings the volumetric fraction evolution in time. Firstly, the structure is $100 \%$ austenite. For a free-stress state, an external loop is obtained through cooling and heating the sample, involving two complete transformations ( $A \Rightarrow M$ and $M \Rightarrow A$ ). After that, a thermal cyclic loading is imposed in such a way that phase transformations are not complete, unless for the last cooling that fully converts the sample in twinned martensite.

Therefore, the simplified version of the model with internal constraints presented is capable of capturing the general thermomechanical behavior of SMA in the same way that the model with assumed transformation kinetics does. It should be pointed out that other phenomena as the TWSME and tensile-compressive asymmetry may also be described by the complete version of the cited model (Paiva et al. [56], Savi and Paiva [65]).

\section{Concluding remarks}

The present contribution discusses the main features inherent to SMAs. Metallurgical aspects are addressed and number of applications are illustrated, attesting SMAs' potential for engineering applications. Numerical simulations for five one-dimensional phenomenological theories are carried out considering pseudoelasticity, shape memory effect, phase transformation phenomenon due to temperature variation, and internal subloops due to incomplete phase transformations. In general, the polynomial model is simple and allow a qualitative description of pseudoelastic and shape memory behavior. Models with assumed phase transformation kinetics are more sophisticated and allows the description of other phenomena, such as the phase transformation due to temperature variations and internal subloops due to incomplete phase transformations. In general, the model proposed by Brinson [13] presents better results than the others. Moreover, the model with internal constraints is capable of capturing the general thermomechanical behavior of SMA in the same way as Brinson's model. 
24 An overview of constitutive models for shape memory alloys

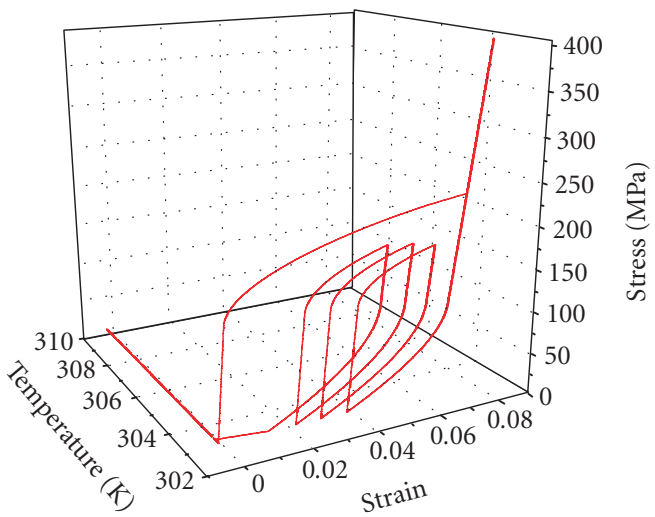

(a)

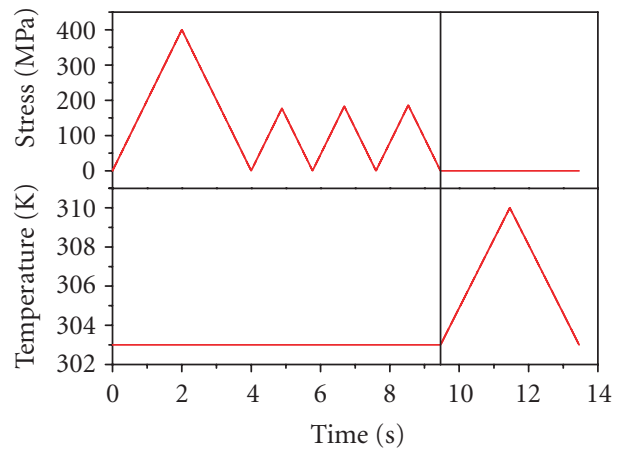

(b)

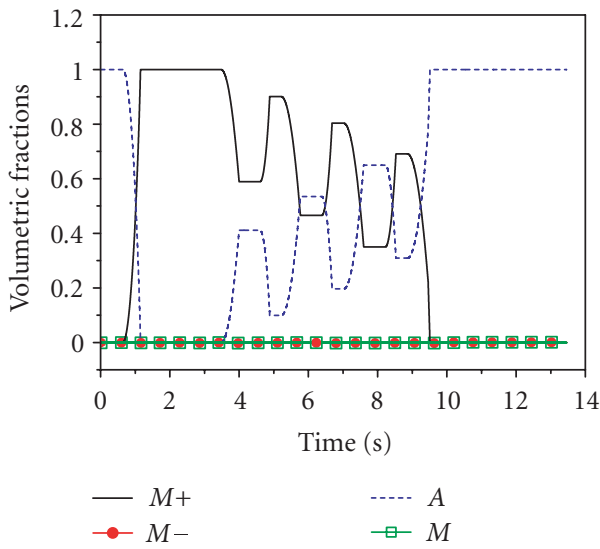

(c)

Figure 6.3. $S M E$ and internal subloops: (a) stress-strain-temperature diagram; (b) thermomechanical loading; (c) volumetric fractions evolution. 


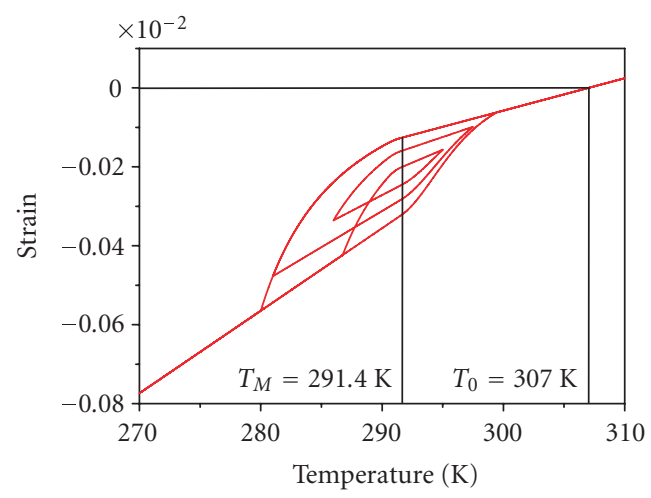

(a)

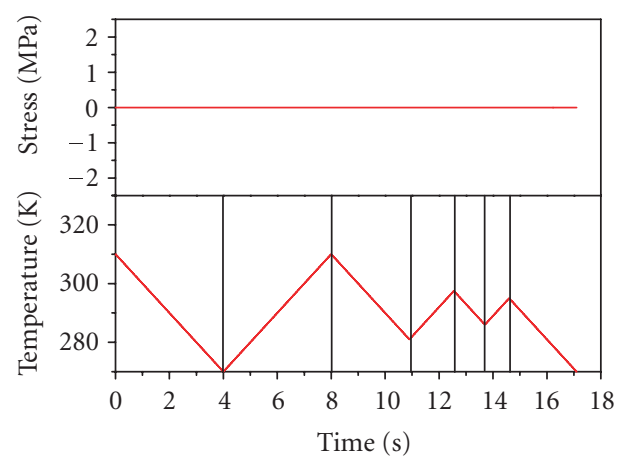

(b)

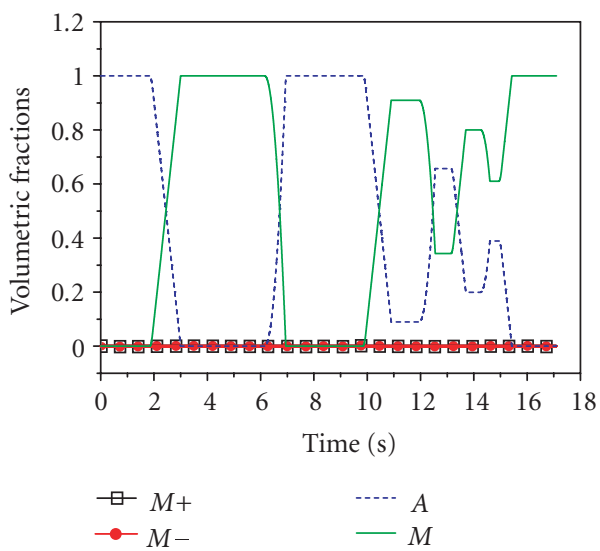

(c)

Figure 6.4. Phase transformation due to temperature variation: (a) strain-temperature diagram; (b) thermomechanical loading; (c) volumetric fractions evolution. 


\section{Acknowledgments}

The authors acknowledge the support of the Brazilian Research Council (CNPq). Special thanks are dedicated to Professor Pedro M. C. L. Pacheco (CEFET/RJ), Professor Arthur M. B. Braga (PUC/Rio), and Alessandro P. Baêta-Neves for their participation in the development of the model with internal constraints. Moreover, the authors acknowledge the contribution of Luciano G. Machado for analyzing shape memory alloys applications.

\section{References}

[1] R. Abeyaratne, S. J. Kim, and J. K. Knowles, A one-dimensional continuum model for shapememory alloys, International Journal of Solids and Structures 31 (1994), no. 16, 2229-2249.

[2] __ Continuum modeling of shape memory alloys, Mechanics of Phase Transformations and Shape Memory Alloys, ASME, New York, 1994a, pp. 59-69.

[3] M. Achenbach and I. A. Müller, A model for shape memory, Journal de Physique 12 (1982), no. 43, 163-167.

[4] W. S. Anders, C. A. Rogers, and C. R. Fuller, Vibration and low-frequency acoustic analysis of piecewise-activated adaptive composite panels, Journal of Composite Materials 26 (1992), 103120.

[5] F. Auricchio and J. Lubliner, A uniaxial model for shape memory alloys, International Journal of Solids and Structures 34 (1997), no. 27, 3601-3618.

[6] F. Auricchio and E. Sacco, A one-dimensional model for superelastic shape memory alloys with different elastic properties between austenite and martensite, International Journal of Non-Linear Mechanics 32 (1997), no. 6, 1101-1114.

[7] F. Auricchio, R. L. Taylor, and J. Lubliner, Shape-memory alloys: macromodeling and numerical simulations of the superelastic behavior, Computer Methods in Applied Mechanics and Engineering 146 (1997), no. 3-4, 281-312.

[8] A. P. Baêta-Neves, M. A. Savi, and P. M. C. L. Pacheco, On the fremond's constitutive model for shape memory alloys, Mechanics Research Communications 31 (2004), no. 6, 677-688.

[9] A. Bertran, Thermo-mechanical constitutive equations for the description of shape memory effects in alloys, Nuclear Engineering and Design 74 (1982), no. 2, 173-182.

[10] V. Birman, Review of mechanics of shape memory alloys structures, Applied Mechanics Review 50 (1997), no. 11, 629-645.

[11] Z. H. Bo and D. C. Lagoudas, Thermomechanical modeling of polycrystalline SMAs under cyclic loading. Part III: evolution of plastic strains and two-way shape memory effect, International Journal of Engineering Science 37 (1999), no. 9, 1175-1203.

[12] J. G. Boyd and D. C. Lagoudas, A thermodynamic constitutive model for the shape memory materials. Part I: the monolithic shape memory alloys, International Journal of Plasticity 12 (1996), no. 6, 805-842.

[13] L. C. Brinson, One dimensional constitutive behavior of shape memory alloys: themomechanical derivation with non-constant material functions and redefined martensite internal variable, Journal of Intelligent Material Systems and Structures (1993), no. 4, 229-242.

[14] S. B. Choi, Y. M. Han, J. H. Kim, and C. C. Cheong, Force tracking of a flexible gripper featuring shape memory alloys actuators, Mechatronics 11 (2001), no. 6, 677-690.

[15] R. J. Comstock Jr., T. E. Buchheit, M. Somerday, and J. A. Wert, Modeling the transformation stress of constrained shape memory alloys single crystals, ACTA Materialia 44 (1996), no. 9, 3505-3514.

[16] I. Dobovsek, On formal structure of constitutive equations for materials exhibiting shape memory effects, shape memory materials, Materials Science Forum 327 (2000), no. 3, 359-362. 
[17] F. Falk, Model free-energy, mechanics and thermodynamics of shape memory alloys, ACTA Metallurgica 28 (1980), no. 12, 1773-1780.

[18] _ One-dimensional model of shape memory alloys, Archives of Mechanics 35 (1983), no. 1, 63-84.

[19] F. Falk and P. Konopka, Three-dimensional Landau theory describing the martensitic transformation of shape memory alloys, Journal de Physique (1990), no. 2, 61-77.

[20] F. D. Fischer, E. R. Oberaigner, K. Tanaka, and F. Nishimura, Transformation induced plasticity revised: an updated formulation, International Journal of Solids and Structures 35 (1998), no. 18, 2209-2227.

[21] F. D. Fischer and K. Tanaka, A micromechanical model for the kinetics of martensitic transformation, International Journal of Solids and Structures 29 (1992), no. 14-15, 1723-1728.

[22] M. Fremond, Matériaux à Mémoire de Forme, Comptes Rendus Mathematique. Academie de Sciences. Paris 304, s.II (1987), no. 7, 239-244.

[23] Shape memory alloy: a thermomechanical macroscopic theory, CISM Courses and Lectures, no. 351, Springer, New York, 1996, pp. 3-68.

[24] H. Funakubo, Shape Memory Alloys, Gordon \& Bleach, New York, 1987.

[25] K. Gall, H. Sehitoglu, R. Anderson, I. Karaman, Y. I. Chumlyakov, and I. V. Kireeva, On the mechanical behavior of single crystal Ni-Ti shape memory alloys and related polycrystalline phenomenon, Materials Science and Engineering A317 (2001), 85-92.

[26] K. Gall, H. Sehitoglu, Y. I. Chumlyakov, and I. V. Kireeva, Tension-compression asymmetry of the stress-strain response in aged single crystal and polycrystalline NiTi, ACTA Materialia 47 (1999), no. 4, 1203-1217.

[27] B. C. Goo and C. Lexcellent, Micromechanics-based modeling of two-way memory effect of a singlecrystalline shape-memory alloy, ACTA Materialia 45 (1997), no. 2, 727-737.

[28] S. Govindjee and G. J. Hall, A computational model for shape memory alloys, International Journal of Solids and Structures 37 (2000), no. 5, 735-760.

[29] S. Govindjee and E. P. Kasper, A shape memory alloy model for uranium-niobium accounting for plasticity, Journal of Intelligent Material Systems and Structures 8 (1997), 815-826.

[30] D. A. Hebda and S. R. White, Effect of training conditions and extended thermal cycling on nitinol two-way shape memory behavior, Smart Materials and Structures 4 (1995), no. 4, 298-304.

[31] D. E. Hodgson and J. W. Brown, Using Nitinol Alloys, Shape Memory Applications, California, 2000.

[32] Y. Ivshin and T. J. Pence, A constitutive model for hysteretic phase transition behavior, International Journal of Engineering Science 32 (1994), no. 4, 681-704.

[33] _ A thermomechanical model for a one variant shape memory material, Journal of Intelligent Material Systems and Structures (1994b), no. 5, 455-473.

[34] P. Kloucek, D. R. Reynolds, and T. I. Seidman, Computational modeling of vibration damping in SMA wires, Continuum Mechanics and Thermodynamics 16 (2004), no. 5, 495-514.

[35] P. K. Kumar, D. C. Lagoudas, and P. B. Entchev, Thermomechanical characterization SMA actuators under cyclic loding, Proccedings of the ASME - International Mechanical Engineering Congress and R \& D Expo, Washington, November 2003.

[36] C. A. P. L. La Cava, E. P. Silva, L. G. Machado, P. M. C. L. Pacheco, and M. A. Savi, Modeling of a shape memory preload device for bolted joints, Proceedings of National Congress of Mechanical Engineering (CONEM 2000 - ABCM), Rio de Janeiro, 2000.

[37] S. Leclercq, G. Bourbon, and C. Lexcellent, Plasticity like model of martensite phase transition in shape memory alloys, Journal de Physique IV 5 (1995), 513-518.

[38] J. Lemaitre and J. L. Chaboche, Mechanics of Solid Materials, Cambridge University Press, Cambridge, 1990. 
[39] V. I. Levitas, A. V. Idesman, E. Stein, J. Spielfeld, and E. Hornbogen, A simple micromechanical model for pseudoelastic behavior of CuZnAl alloy, Journal of Intelligent Material Systems and Structures (1998), no. 5, 324-334.

[40] C. Lexcellent, S. Leclercq, B. Gabry, and G. Bourbon, The two-way shape memory effect of shape memory alloys: an experimental study and a phenomenological model, International Journal of Plasticity 16 (2000), no. 10-11, 1155-1168.

[41] C. Liang and C. A. Rogers, One-dimensional thermomechanical constitutive relations for shape memory materials, Journal of Intelligent Material Systems and Structures (1990), no. 1, 207234.

[42] T. J. Lim and D. L. McDowell, Degradation of an Ni-Ti alloy during cyclic loading, Proceedings of 1994 North American Conference on Smart Structures and Materials, SPIE, vol. 2189, 1994, pp. 326-341.

[43] Z. K. Lu and G. J. Weng, A Self-consistent model for the stress-strain behavior of shape-memory alloy polycrystals, ACTA Materialia 46 (1998), no. 15, 5423-5433.

[44] L. G. Machado, Chaos in dynamical systems with shape memory and multi-degree of freedom, Master's thesis, IME—Department of Mechanical and Materials Engineering, 2002.

[45] L. G. Machado and M. A. Savi, Odontological applications of shape memory alloys, Revista Brasileira de Odontologia 59 (2002), no. 5, 302-306.

[46] Medical applications of shape memory alloys, Brazilian Journal of Medical and Biological Research 36 (2003), no. 6, 683-691.

[47] O. Matsumoto, S. Miyazaki, K. Otsuka, and H. Tamura, Crystallography of martensitic transformation in Ti-Ni single crystals, ACTA Metallurgica 35 (1987), no. 8, 2137-2144.

[48] D. A. Miller and D. C. Lagoudas, Thermomechanical characterization of NiTiCu and NiTi SMA actuators: influence of plastic strains, Smart Materials and Structures 9 (2000), no. 5, 640-652.

[49] I. Muller and S. Seelecke, Thermodynamic aspects of shape memory alloys, Mathematical and Computer Modelling 34 (2001), no. 12-13, 1307-1355.

[50] F. Nishimura, N. Watanabe, and K. Tanaka, Transformation lines in an Fe-based shape memory alloy under tensile and compressive stress states, Materials Science and Engineering A22 (1996), $134-142$.

[51] Stress-strain-temperature hysteresis and martensite start line in an Fe-based shape memory alloy, Materials Science and Engineering. A-Structural Materials Properties Microstructure and Processing 238 (1997), no. 2, 367-376.

[52] Z. Nishiyama, Martensitic Transformation, Academic Press, New York, 1978.

[53] M. Ortiz, P. M. Pinsky, and R. L. Taylor, Operator split methods for the numerical solution of the elastoplastic dynamic problem, Computer Methods of Applied Mechanics and Engineering 39 (1983), no. 2, 137-157.

[54] K. Otsuka and X. Ren, Recent developments in the research of shape memory alloys, Intermetallics 7 (1999), no. 5, 511-528.

[55] P. M. C. L. Pacheco and M. A. Savi, A non-explosive release device for aerospace applications using shape memory alloys, Proceedings of XIV Brazilian Mechanical Engineering Congress, Sao Paulo, December 1997.

[56] A. Paiva, M. A. Savi, A. M. B. Braga, and P. M. C. L. Pacheco, A constitutive model for shape memory alloys considering tensile-compressive asymmetry and plasticity, International Journal of Solids and Structures 42 (2005), no. 11-12, 3439-3457.

[57] J. Perkins, Shape Memory Effects in Alloys, Plenum Press, New York, 1975.

[58] P. Prader and A. C. Kneissl, Deformation behavior and two-way shape-memory effect of NiTi alloys, Zeitschrift fur Metallkunde 88 (1997), 410-415. 
[59] RAYCHEM-TYCO ELECTRONIC CORPORATION, captured on 04/29/2001, http://www. raychem.com.

[60] O. K. Rediniotis, L. N. Wilson, D. C. Lagoudas, and M. M. Khan, Development of a shapememory-alloy actuated biomimetic hydrofoil, Journal of Intelligent Material Systems and Structures 13 (2002), no. 1, 35-49.

[61] R. T. Rockafellar, Convex Analysis, Princeton Mathematical Series, no. 28, Princeton University Press, New Jersey, 1970.

[62] C. A. Rogers, Intelligent materials, Scientific American (1995), 122-127.

[63] C. A. Rogers, C. Liang, and C. R. Fuller, Modeling of shape memory alloy hybrid composites for structural acoustic control, Journal of Acoustic Society of America 89 (1991), no. 1, 210-220.

[64] M. A. Savi and A. M. Braga, Chaotic vibration of an oscillator with shape memory, Journal of the Brazilian Society of Mechanical Science 15 (1993), no. 1, 1-20.

[65] M. A. Savi and A. Paiva, Describing internal subloops due to incomplete phase transformations in shape memory alloys, Archive of Applied Mechanics 74 (2005), no. 9, 637-647.

[66] M. A. Savi, A. Paiva, A. P. Baêta-Neves, and P. M. C. L. Pacheco, Phenomenological modeling and numerical simulation of shape memory alloys: a thermo-plastic-phase transformation coupled model, Journal of Intelligent Material Systems and Structures 13 (2002), no. 5, 261-273.

[67] J. A. Shaw and S. Kyriakides, Thermomechanical aspects of NiTi, Journal of the Mechanics and Physics of Solids 43 (1995), no. 8, 1243-1281.

[68] E. P. Silva, Modelagem Mecânica De Transformações De Fase Induzidas Por Tensões Em Sólidos, Master's thesis, Department of Mechanical Engineering, University of Brasilia, Brasilia, 1995.

[69] J. C. Simo and R. L. Taylor, A return mapping algorithm for plane stress elastoplasticity, International Journal for Numerical Methods in Engineering 22 (1986), no. 3, 649-670.

[70] SINTEF, Shape Memory Alloys in Oil Well Applications, 1999.

[71] P. Sittner and V. Novák, Anisotropy of martensitic transformations in modeling of shape memory alloy polycrystals, International Journal of Plasticity 16 (2000), no. 10-11, 1243-1268.

[72] P. Sittner, V. Novák, and N. Zárubová, Martensitic transformations in [001] Cu-Al-Zn-Mn single crystals, ACTA Materialia 46 (1998), no. 4, 1265-1281.

[73] P. Sittner, V. Novák, N. Zárubová, and V. Studnicka, Stress state effect on martensitic structures in shape memory alloys, Materials Science and Engineering A273-275 (1999), 370-374.

[74] A. C. Souza, E. Mamiya, and N. Zouain, Three-dimensional model for solids undergoing stressinduced phase transformations, European Journal of Mechanics - A Solids 17 (1998), no. 5, 789806.

[75] Q. P. Sun and K. C. Hwang, Micromechanics modeling for the constitutive behavior of polycrystalline shape memory alloys - part I. Derivation of general relations, Journal of the Mechanics and Physics of Solids 41 (1993), no. 1, 1-17.

[76] _ Micromechanics modeling for the constitutive behavior of polycrystalline shape memory alloys - part II. Study of individual phenomenon, Journal of the Mechanics and Physics of Solids 41 (1993b), 19.

[77] K. Tanaka, A thermomechanical sketch of shape memory effect: one-dimensional tensile behavior, Materials Science Research International 18 (1985), 251.

[78] K. Tanaka and S. Nagaki, Thermomechanical description of materials with internal variables in the process of phase transitions, Ingenieur-Archive 51 (1982), 287-299.

[79] K. Tanaka, F. Nishimura, and H. Tobushi, Phenomenological analysis on subloops in shape memory alloys due to incomplete transformations, Journal of Intelligent Material Systems and Structures 5 (1994), 387-493.

[80] R. Vaidyanathan, H. J. Chiel, and R. D. Quinn, A hydrostatic robot for marine applications, Robotics and Autonomous Systems 30 (2000), no. 1-2, 103-113. 
[81] J. van Humbeeck, Non-medical applications of shape memory alloys, Materials Science and Engineering A 273-275 (1999), 134-148.

[82] H. Warlimont, L. Delaey, R. V. Krishnan, and H. Tas, Thermoelasticity, pseudoelasticity and the memory effects associated with martensitic transformations — part 3: thermodynamics and kinetics, Journal of Materials Science 9 (1974), no. 9, 1545-1555.

[83] R. J. Wasilevski, On the nature of the martensitic transformation, Mettalurgical Transactions 6A (1975), 1405-1418.

[84] K. Williams, G. Chiu, and R. Bernhard, Adaptive-passive absorbers using shape memory alloys, Journal of Sound and Vibration 249 (2002), no. 5, 835-848.

[85] S. K. Wu and H. C. Lin, Recent development of NiTi-based shape memory alloys in Twain, Materials Chemistry and Physics 64 (2000), no. 2, 81-92.

[86] S. Zhang and P. G. McCormick, Thermodynamic analysis of shape memory phenomena-I. Effect of transformation plasticity on elastic strain energy, ACTA Materialia 48 (2000), no. 12, 30813089.

[87] _ Thermodynamic analysis of shape memory phenomena_II. Modelling, ACTA Materialia 48 (2000), no. 12, 3091-3101.

[88] X. D. Zhang, C. A. Rogers, and C. Liang, Modeling of two-way shape memory effect, Smart Structures and Material-ASME, New York, December 1991, pp. 79-90.

Alberto Paiva: Department of Mechanical Engineering, Alberto Luiz Coimbra Institute-Graduate School and Research in Engineering (COPPE), Federal University of Rio de Janeiro, P.O. Box 68503, 21941-972 Rio de Janeiro, RJ, Brazil

E-mail address: paiva@lavi.coppe.ufrj.br

Marcelo Amorim Savi: Department of Mechanical Engineering, Alberto Luiz Coimbra Institute-Graduate School and Research in Engineering (COPPE), Federal University of Rio de Janeiro, P.O. Box 68503, 21941-972 Rio de Janeiro, RJ, Brazil

E-mail address: savi@ufrj.br 


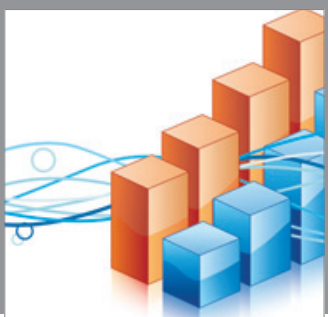

Advances in

Operations Research

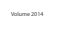

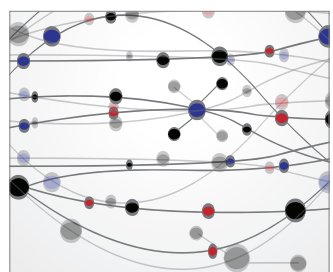

\section{The Scientific} World Journal
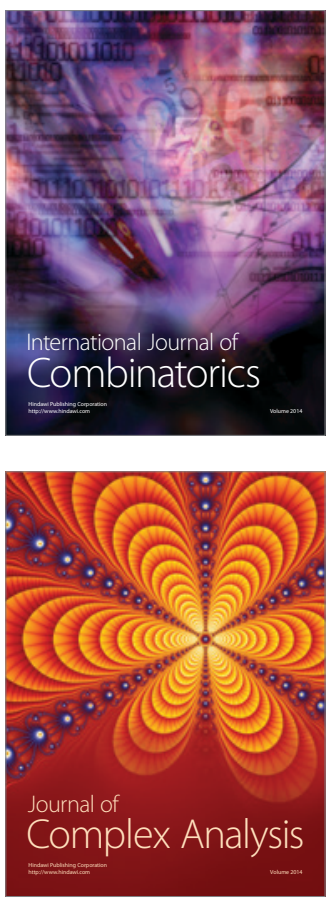

International Journal of

Mathematics and

Mathematical

Sciences
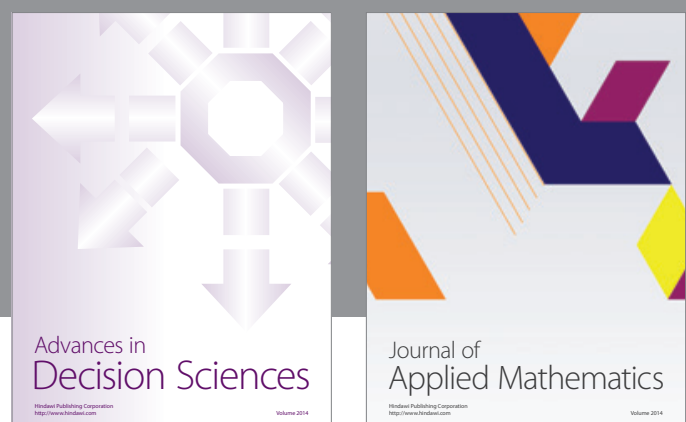

Journal of

Applied Mathematics
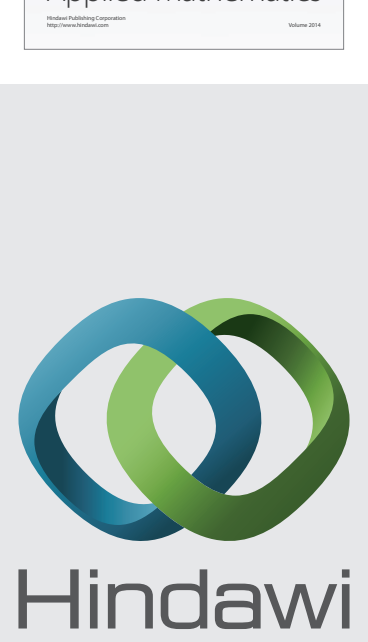

Submit your manuscripts at http://www.hindawi.com
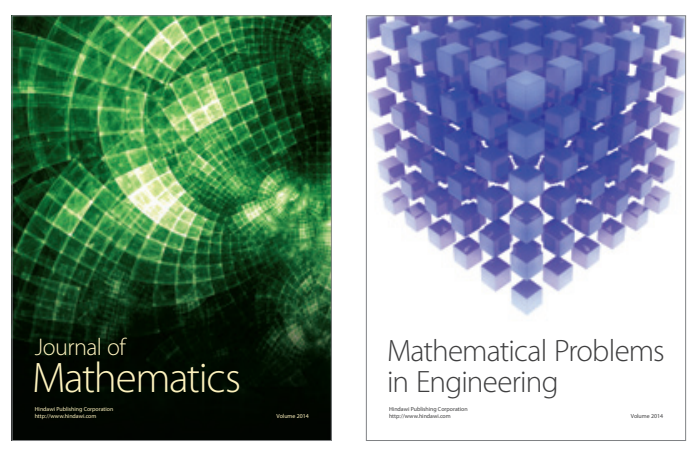

Mathematical Problems in Engineering
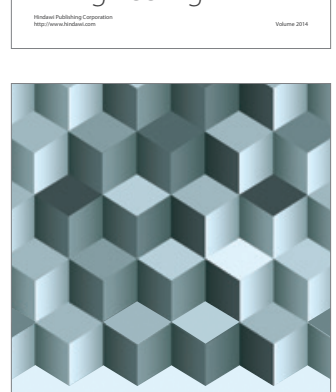

Journal of

Function Spaces
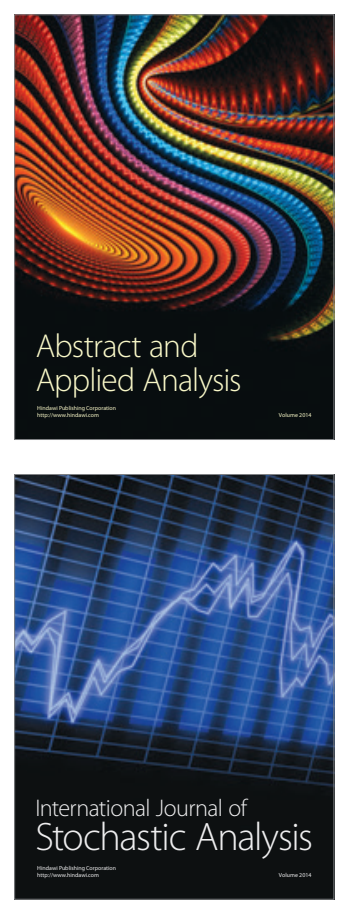

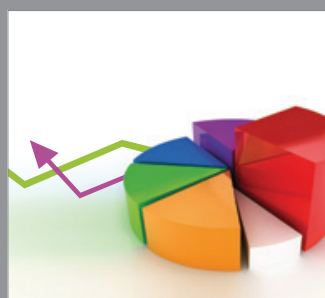

ournal of

Probability and Statistics

Promensencen
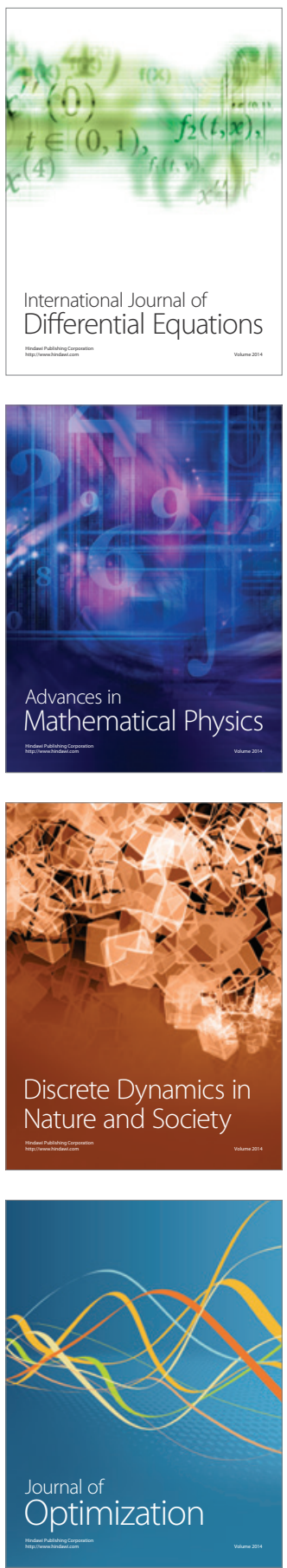